\title{
DRAFT
}

\section{Disability, Rights and Vulnerability in British Parliamentary Debate}

\author{
Evan Odell ${ }^{\mathrm{a}}$

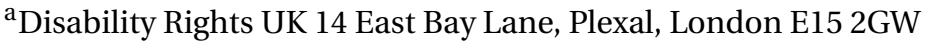

\section{ARTICLE HISTORY}

Compiled July 10, 2018

\begin{abstract}
This paper examines discussion of disability and disabled people by Members of Parliament (MPs) in the UK House of Commons from 1979-2017. It examines general trends in the number of speeches mentioning disability, including the parties and MPs most likely to mention disability issues, and examines how disability is used in conjunction with two keywords: 'rights' and 'vulnerable'. It uses these keywords to explore two conceptions of how the state should engage with disability and disabled people: a paternalistic conception (which post-2010 has become more common) and a rights-based conception (which has been in decline since the 1990s). I conclude with a discussion about how this reflects the disability movement in the UK, and what it means for the future of disability politics, the welfare state and how disabled people themselves might view paternalistic government policies.
\end{abstract}

\author{
Abbreviations: \\ SNP: Scottish National Party \\ DPAC: Disabled People Against the Cuts \\ MP: Member of Parliament \\ KWIC: Key Words in Context
}

\section{KEYWORDS}

Disability, Politics, Hansard, Political Discourse

\section{Introduction}

The way politicians approach, discuss and debate an issue can reveal how that given issue is viewed, and the predict the policy responses to that issue. The tone of political rhetoric both informs and reflects popular conceptions, media coverage and public policies on a given issue or set of issues. Discourse, amongst politicians, mass media and the general public, has been a long-standing concern in the field of disability studies, particularly focusing on popular descriptions of disability and how these can harm (or help) disabled people, or the language and arguments used by governments to 'sell' different policies.

This paper explores a new way of approaching political discourse on disability, both methodologically and conceptually. It focuses on the concepts of rights and paternalism, as applied to disabled people and disability issues generally in speeches by Members of Parliament (MPs) in the UK House of Commons over a period from 1979-2017.

Disability studies has been slow to engage with computational linguistics and its potential to improve our understanding of disability, particularly attitudes towards disabil- 
ity. Existing research on discussion and portrayal of disability in political and popular discourse has involved relatively narrow time frames and small sample sizes, with researchers hand coding newspaper articles to identify problematic language (e.g. Briant, Watson, and Philo 2013: Haller, Dorries, and Rahn, 2006), or haphazard analysis of political rhetoric (e.g. Garthwaite, 2011). There is often been a focus on - or at least reference to - disabled people as either 'deserving' or 'undeserving' of welfare benefits or societal participation.

I do not mean to denigrate existing research, but to recognise its limitations and build upon it, and attempt to use relatively more systematic methods of analysing discourse on disability, focusing on the language used by one of the most important political actors - lawmakers themselves - when discussing disability issues. I want to see if policy changes have prompted changes in political discourse and debate, using discourse as a consequence of policy changes, rather than a driving force. It seems self-evident that government policies are able to shift political debate; the government changes its language to reflect and justify its policies, and opposition and backbench MPs in turn take up that language to criticise or influence the government.

The method employed in this paper is a simple, descriptive kind of computational linguistics, focusing on the frequency with which disability is mentioned in parliamentary debate, and quantifies the usage of paternalistic and aspirational language when discussing disability in order to identify broader trends.

This study covers 39 years of parliamentary debate, 39 years in which the terminology around disability has changed considerably, as has parliamentary debate, with the language used by both government and opposition MPs becoming persistently more positive since the early 1980s (Rheault et al. 2016). For example Scope, one of the largest disability charities in the UK, was known as the Spastic Society until 1994. It is also a time period that saw the International Year of Disabled People (in 1981), the rise of Disabled Persons Organisations (DPOs) and other forms of disability activism, the promulgation of the social model of disability (Oliver. 1983), and the passage of landmark legislation, most notably the Disability Discrimination Act (1995) and the Equality Act (2010).

\section{Disability and discourse literature}

Discourse analysis on disability and related topics - at least in the British context - focuses on two main objects of study: firstly, media coverage and portrayals, and secondly, government policies and services themselves. The majority of discourse analyses on and about disabled people have focused on mass media, typically newspaper coverage or depictions of disability in popular television. The cultural turn in the social sciences and humanities, combined with disability-specific arguments for greater cultural analysis (e.g. Shakespeare 1994), have had a substantial impact on disability studies (Waldschmidt, 2017).

Briant, Watson, and Philo (2013) found fewer sympathetic articles on disability issues in British newspapers in 2010-2011, compared to 2004-2005, and the emergence of what they termed a 'folk devil' narrative (880). Haller, Dorries, and Rahn (2006) found that coverage of disability issues in two major American newspapers - The New York Times and The Washington Post - frequently used negative-stereotype terms like 'The disabled' throughout the 1990s, despite the high-profile passage of the Americans with Disabilities Act. Braye, Dixon, and Gibbons (2013) explored the scepticism and 'cynicism' of the 2012 Paralympics and associated media coverage amongst disability activists. The 'narrow' range of disabled characters in popular television shows has been widely criticised (for example by Wilde. 2014), and the concept of 'poverty porn' (Jensen, 2014) is highly applicable when examining mass media coverage of disabled people. The influence of mass media coverage of 
disability issues on politics - and vice versa - is unclear, and cannot serve as a proxy for political discourse and decisions.

Studies of policy discourse focusing exclusively on disability appear to be unusual, and disability is often lumped in with related topics such as unemployment benefits or social care, in studies of government policy documents and legislation (e.g. Garrett, 2015 Jensen and Tyler, 2015 Roulstone and Morgan, 2009). Policy discourse research can be further divided into studies of specific legislation or policy decisions, such as the Welfare Reform Act (2012) (Jensen and Tyler. 2015) or the closure of Remploy factories (Connor. 2010), and broader trends in policy and practice, such as New Labour's attempts at policy reform (Donoghue, 2013) or Margaret Thatcher's attempt to change the terms of social policy debate to secure political legitimacy and the continuity of her welfare reform projects in future governments (Schmidt 2002). Garthwaite (2011) is somewhat unique in examining the actual language used by politicians, namely then-Secretary of State for Work and Pensions Iain Duncan Smith and then-employment minister Chris Grayling. However, this analysis takes the form of a comment piece reflecting a general impression of political discourse shared by many disability activists and researchers, rather than a systematic analysis of political rhetoric.

\section{Methods}

The data used in this analysis was taken from the 'Hansard Speeches and Sentiment V2.4.1' dataset (?), covering every speech made in the House of Commons between 9 May 1979 and 20 July 2017, along with the name, party, and parliamentary ID number of the speaker. Unless otherwise indicated (i.e. where displaying the number of speeches per year) all charts in this article cover 9 May 1979 to 20 July 2017. There are 25,698 speeches in that time period with some reference to disability, containing one or more of the terms 'disabled', 'disability', 'disablement' or 'disabling' 1 Speeches ranged from 3 to 8,768 words in length. $1.18 \%$ of all speeches made in parliament from 9 May 1979 to 20 July 2017 contained a disability term. To identify speeches with paternalistic approaches to disability, I used the word 'vulnerable' and its stem ('vulner'). 3,236 of those speeches also included the term 'rights', and 2,136 included a stem for 'vulnerable'.

Analysis was conducted using the R programming language, with ggplot2 (Wickham 2016) used to create the graphics used in this article. Collocates were identified using the quanteda package (Benoit et al. 2017).

\subsection{Limitations}

Parliamentary speeches are only one form of political discourse, and MPs are only one group of political actors. This paper excludes entirely the House of Lords, parliamentary committees, debates in Westminster Hall, not to mention speeches, articles and comments by political actors outside of Parliament.

This analysis focused on just two terms used to talk about disabled people, which only feature in a small proportion of all speeches about disability. There are countless more examples of affirmative or paternalistic words and phrases used to talk about disabled people which this analysis does not include. I have not engaged in

There is a possibility of false positives, where disability-related terms are not used to refer to disability or disabled people. Given the size of the dataset involved, it was not pos-

\footnotetext{
${ }^{1}$ The term 'disable' does occur in Hansard, but is used in reference to technology or injuries, rather than disability.
} 
sible to ensure that all uses referred to disabled people, although every effort has been made to screen for false positives. There is also a possible confounding factor stemming from the use of rights in the names of bills (such as the Civil Rights (Disabled Persons) private members bills introduced in the House of Commons in the 1990s) and organisations (such as Disability Rights UK or the now defunct Disability Rights Commission) that may be referred to in parliamentary speeches. There do not appear to be equivalents using the term vulnerable. I decided not to remove these legislative and organisational references to rights, as references to a rights-based piece of legislation or the work of a rights campaigning organisation in the context of disability are likewise references to the rights-based conception of disability set out below.

\section{Who talks about disability?}

The percentage of speeches in parliamentary mentioning disability have increased from 1979-2017. There are several substantial spikes, most notably in 1995, in debate over the Disability Discrimination Act (where $2.20 \%$ of speeches mentioned disability), and in 2016, as the impact of austerity on disabled people became a popular topic for opposition parties, particularly the SNP (see Figure 1 for all mentions of disability, Figure 4 for mentions of disability by party group and Figure 5 for mentions of disability by government status). $1.84 \%$ of speeches in 2016 mentioned disability, including $3.18 \%$ of all speeches made by the SNP. The percentage of speeches each year that mention disability have generally increased over time, but the trend is not consistent. In 1982, only $0.71 \%$ of speeches mentioned disability, the lowest of any full year in the dataset, though only $0.72 \%$ mentioned disability in 2003.

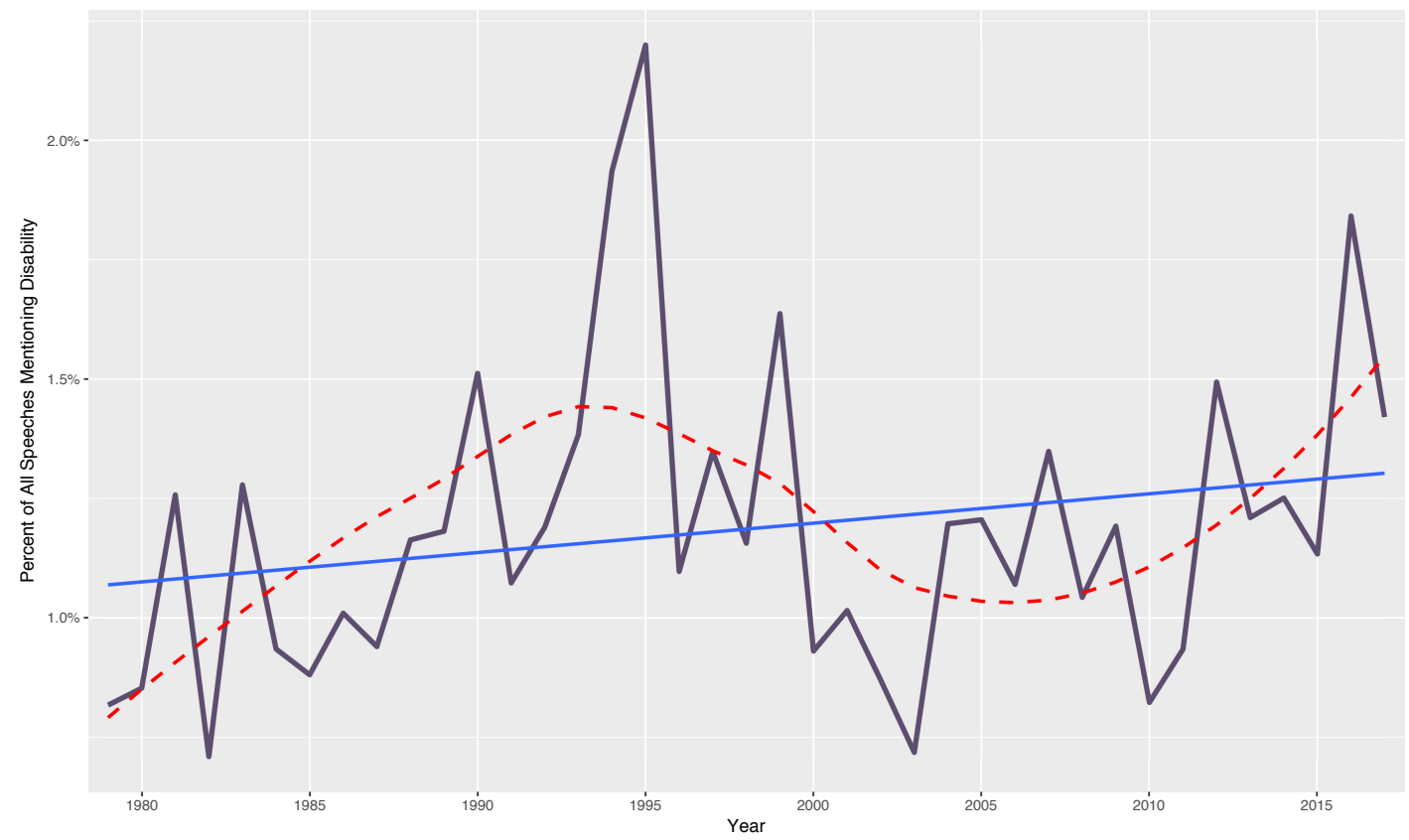

Figure 1. Percentage of all speeches made in parliament mentioning disability. 
Table 1. All MPs who make some reference to disability during at least $10 \%$ of their speeches, and who have made at least 100 speeches in the House of Commons.

\begin{tabular}{|c|c|c|c|c|}
\hline Name & Party & $\begin{array}{l}\text { Number of Speeches } \\
\text { Referencing Disability }\end{array}$ & Total Speeches & $\begin{array}{l}\text { Percentage of Speeches } \\
\text { Referencing Disability }\end{array}$ \\
\hline Alfred Morris* & Labour & 418 & 1064 & $39.29 \%$ \\
\hline Roger Berry & Labour & 181 & 531 & $34.09 \%$ \\
\hline Jack Ashley & Labour & 216 & 736 & $29.35 \%$ \\
\hline John Hannam & Conservative & 174 & 668 & $26.05 \%$ \\
\hline Lisa Cameron $^{\dagger}$ & SNP & 34 & 184 & $18.48 \%$ \\
\hline Neil Gray & SNP & 38 & 206 & $18.45 \%$ \\
\hline Elizabeth Lynne & Liberal Democrat & 87 & 477 & $18.24 \%$ \\
\hline Neil Coyle $^{\dagger}$ & Labour & 18 & 103 & $17.48 \%$ \\
\hline Nicholas Scott* & Conservative & 411 & 2358 & $17.43 \%$ \\
\hline Lewis Carter-Jones & Labour & 71 & 424 & $16.75 \%$ \\
\hline Anne McGuire* ${ }^{*}$ & Labour & 159 & 1009 & $15.76 \%$ \\
\hline Anne Begg & Labour & 144 & 921 & $15.64 \%$ \\
\hline Debbie Abrahams* $†$ & Labour & 107 & 733 & $14.60 \%$ \\
\hline Esther McVey* $†$ & Conservative & 90 & 618 & $14.56 \%$ \\
\hline Maria Miller* ${ }^{*}$ & Conservative & 252 & 1812 & $13.91 \%$ \\
\hline Tom Benyon & Conservative & 17 & 125 & $13.60 \%$ \\
\hline Eilidh Whiteford & SNP & 86 & 637 & $13.50 \%$ \\
\hline Gordon McMaster $^{\dagger}$ & Labour & 32 & 240 & $13.33 \%$ \\
\hline Tom Clarke* & Labour & 323 & 2554 & $12.65 \%$ \\
\hline Justin Tomlinson ${ }^{*} \dagger$ & Conservative & 74 & 601 & $12.31 \%$ \\
\hline Paul Maynard $^{\dagger}$ & Conservative & 58 & 498 & $11.65 \%$ \\
\hline Alan Howarth & Conservative/Labour & 127 & 1110 & $11.44 \%$ \\
\hline Joan Humble & Labour & 49 & 433 & $11.32 \%$ \\
\hline Kate Green ${ }^{\dagger}$ & Labour & 113 & 1053 & $10.73 \%$ \\
\hline Dafydd Wigley & Plaid Cymru & 269 & 2603 & $10.33 \%$ \\
\hline
\end{tabular}

Names marked with a $\dagger$ are MPs who were members of the House of Commons after the 2017 General Election. Names marked with $\mathrm{a}^{*}$ are MPs who have served as minister or shadow minister for disabled people, or equivalent.

\section{1. $M P S$}

As expected, some MPs mention disability in parliament far more than others. Table 1 lists the 25 MPs who make some reference to disability during at least $10 \%$ of their speeches, and who have made at least 100 speeches in the House of Commons between the 1979 General Election and the 2017 summer recess. 12 are from Labour, seven from the Conservatives, three from the SNP, one each from Plaid Cymru and the Liberal Democrats, and a single MP (Alan Howarth) who was first elected as a Conservative and then crossed the floor to Labour 2

These 25 MPs made $1.00 \%$ of all speeches in the dataset, but $13.71 \%$ of all speeches that referenced disability, and includes several MPs who held positions as the Minister and/or Shadow Minister for Disabled People (or equivalent), marked with an asterisk. Other MPs, such as Jack Ashley and John Hannam, while not holding formal minister or shadow minister positions, are noted campaigners on disability issues inside and outside parliament. John Hannam and Lisa Cameron have both served as the chair of the All Party Parliamentary Group on Disability.

Not all MPs who had an apparent interest in disability prior to being elected carried that forward into parliament, at least based on their Hansard speeches. For example, Tim Yeo, Conservative MP from South Suffolk from 1983-2015, who prior to becoming an MP was the chief executive of the Spastics Society from 1980-1983 mentioned disability in $1.67 \%$ of all speeches he made in the House of Commons.

There are variations in the percentage of MPs mentioning disability in each parliament

${ }^{2}$ Alan Howarth changed parties in 1995, crossing the floor from the Conservatives to Labour. For a table broken down by his time in each party, see Table 4 
(divided by general elections), although this coincides in some ways with the length of each parliament. The parliaments where the greatest proportion of MPs mentioned disability at least once were John Major's second ministry from 1992-1997 (78.3\% of all MPs) and David Cameron's first ministry, in coalition with the Liberal Democrats from 2010-2015 (81.4\%). John Major's second ministry saw the passing of the 1995 Disability Discrimination Act, which, as seen in Figure 1, was a high point for the percentage of speeches mentioning disability, as well as speeches mentioning disability and rights (Figure 12.

David Cameron's first ministry saw the implementation of the government's austerity programme of public sector spending reductions, which included substantial reforms of disability policies, including increasing conditionality and means testing for many disability benefits, and continued by the post-2015 General Election Conservative government. Reforms included the closure of the Independent Living Fund, the replacement of the Disability Living Allowance (DLA) with Personal Independence Payments (PIP), the reassessment of Employment and Support Allowance (ESA) recipients, real-terms cuts to adult social care (Luchinskaya, Simpson, and Stoye, 2017, 166) and a general retrenchment of welfare state programmes which have arguably had a disproportionate impact on disabled people (see below).

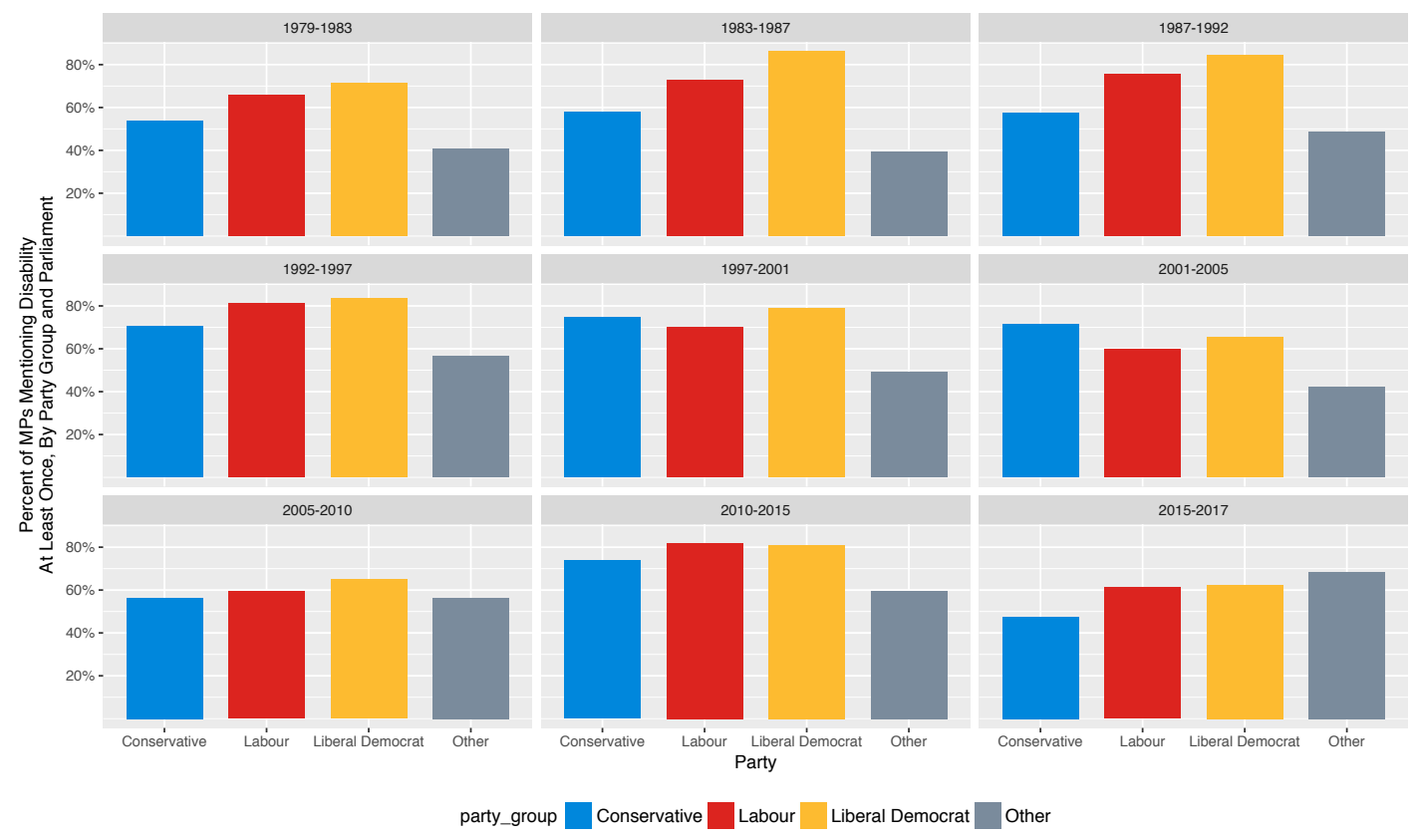

Figure 2. Percentage of all MPs mentioning disability at least once, per Parliament and Party Group.

\subsection{Gender}

Female MPs first overtook male MPs in the percentage of all speeches mentioning disability at least once in 1999, and have been more likely to reference disability from 2001 onwards. The percentage of female MPs almost doubled in 1997, and has more or less increased since then. There have been proportionally more female MPs from the Labour Party, Plaid Cymru and the SNP (Audickas, Hawkins, and Cracknell. 2017), all parties whose MPs are more likely to mention disability than the Conservatives or other smaller parties, as illustrated in Figure 4 . Ten of the 25 MPs who most frequently mention disability are 
women (see Table 1), despite only $18.3 \%$ of all MPs being women in the time period covered.

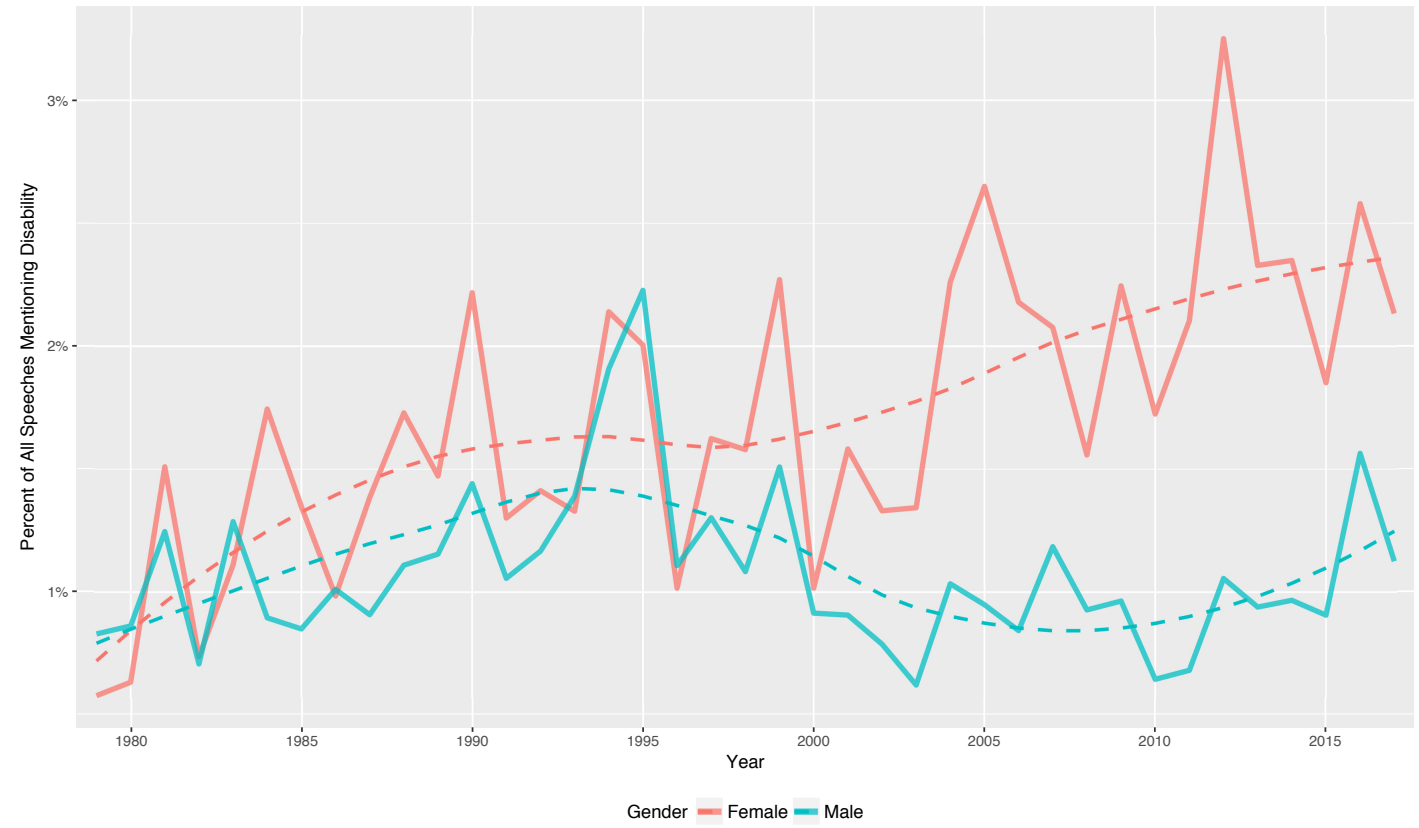

Figure 3. Percentage of all speeches made in parliament mentioning disability, by gender. The dashed lines represent a fitted model with LOESS smoothing.

\subsection{Parties}

The 'Hansard Speeches and Sentiment V2.4.1' dataset contains a 'Party Group' variable, which keeps the Conservatives and Labour as their own distinct categories, groups the main third parties during most of the period covered (the Liberals, the Social Democrats and the Liberal Democrats) into the Liberal Democrat party, and classifies all other MPs as Other. From the 2015 General Election onwards (when the SNP went from 6 to 56 MPs) I have separated the SNP from the 'Other' parties and included them in party visualisations, as they overtook the Liberal Democrats to become the third largest party in the House of Commons, and as made substantial numbers of speeches on disability in that time. It is unclear what prompted the SNP's frequent mentioning of disability; $19.65 \%$ of people in Scotland have a disability or long-term health condition, a slightly higher rate than the UK as a whole, but less than both Wales and Northern Ireland (Office for National Statistics, National Records of Scotland, and Northern Ireland Statistics and Research Agency, 2017). It may be that, having captured a swath of seats previously held by Labour, the SNP may be trying to seize the mantle of 'champion of the vulnerable' that is a core of the Labour Party's political identity.

\subsection{Government}

Disability was referenced more frequently by the government when Labour was in power Figure 5, unsurprising given Labour's association with the topic generally. However, Labour's period in government saw - overall - a decline in mentions of disability compared to earlier in the 1990s and post-2010. Some of this decline is likely because the years 


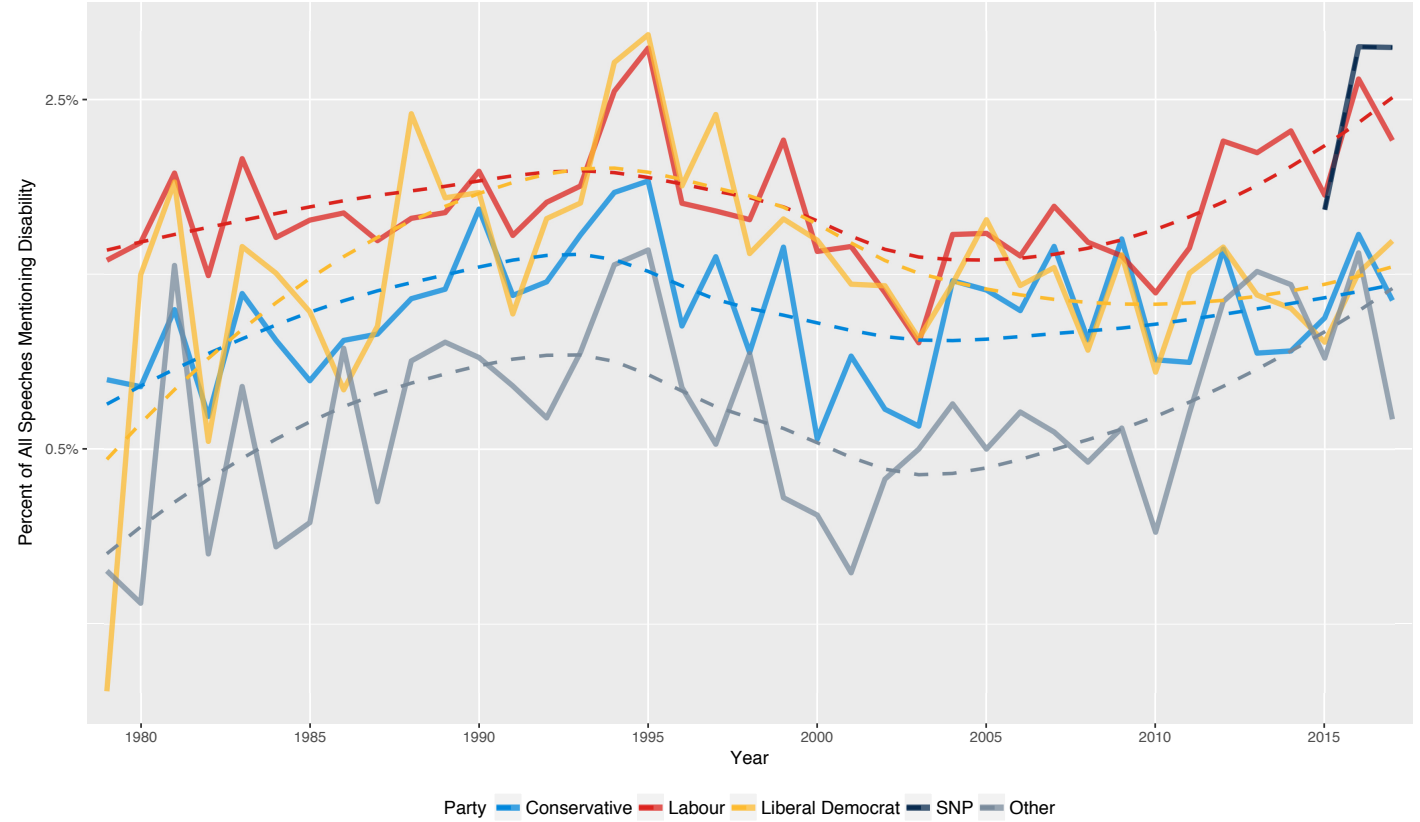

Figure 4. Percentage of all speeches made in parliament mentioning disability, by party group. The dashed lines represent a fitted model with LOESS smoothing. Note the logarithmic scale on the $\mathrm{x}$ axis.

after the passage of the Disability Discrimination Act 1995 saw 'fatigue' with the topic of disability, and there were fewer substantive aims that political campaigners believed they could achieve.

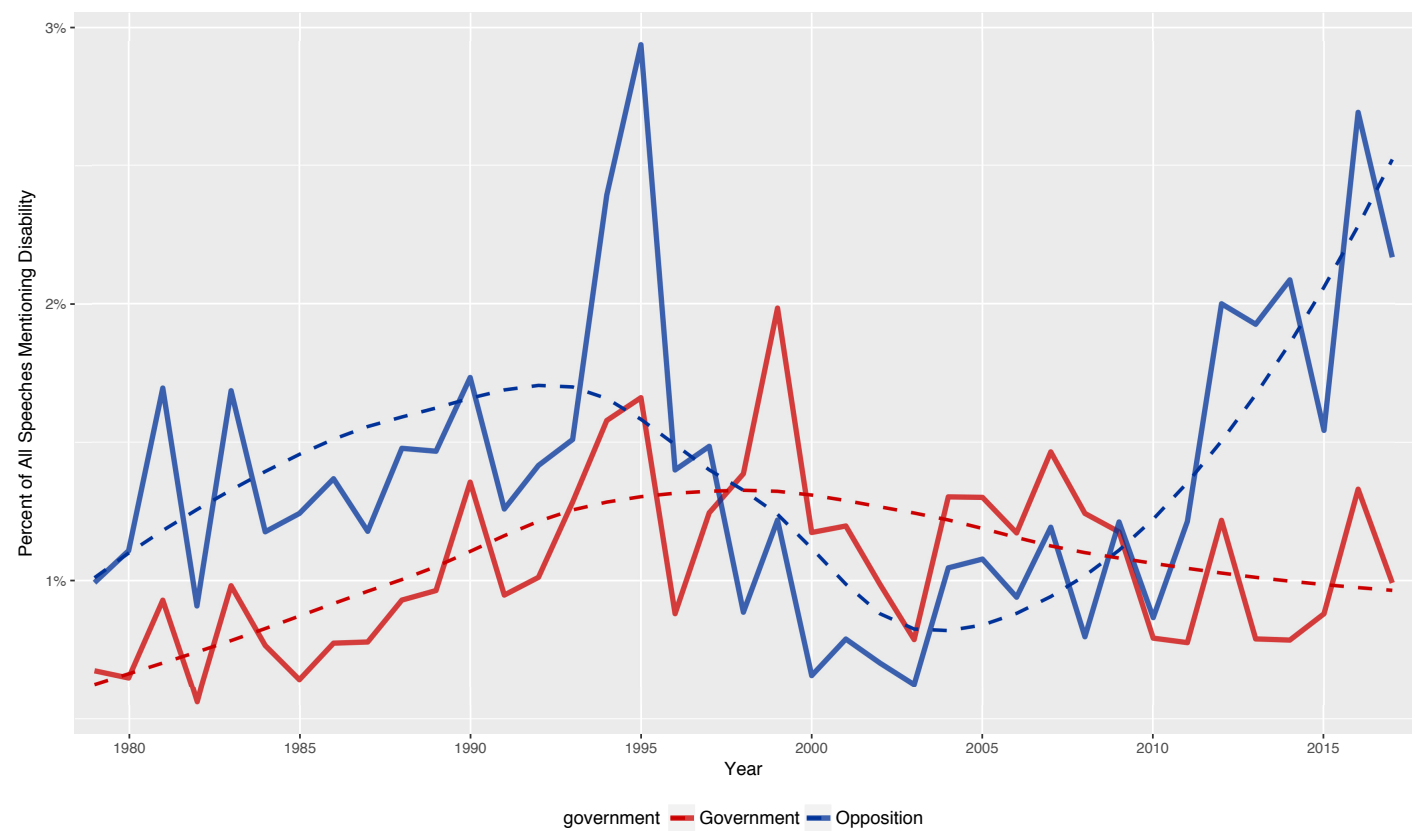

Figure 5. Percentage of all speeches made in parliament mentioning disability, by government status. The dashed lines represent a fitted model with LOESS smoothing. 


\section{Two concepts of disability: 'rights' and 'paternalism'}

There are three primary models of disability used in disability research: the social model, as proposed by Oliver (1983) to contrast with the traditional medical model, and the affirmative model of Swain and French (2000). I am not adopting a particular model; instead I am using what I call conceptions, to represent ideological understandings of disability and disabled people, specifically in terms of how they are treated by society and the state. This paper focuses on two conceptions of disability and disabled people: a 'rights' conception, and a 'paternalist' conception, as used by MPs in debate in the House of Commons. The rights conception emphasises societal participation and views the state's role as ensuring disabled people can access their rights and participate in society on the same basis as everyone else. The paternalist conception is more (small-c) conservative, with a state responsible for protecting disabled people from harm, potentially including harms above and beyond what non-disabled people are protected from.

Focusing on rights and paternalism, rather than 'shirkers and scroungers' (Garthwaite. 2011), also gets beyond the problem of 'deserving' and 'undeserving'. Rather than dividing discourse along an axis of positive and negative views of disability and disabled people, I divide it between condescension and encouragement. This more closely matches actual political opinions on disability; the rhetorical claims of some disability activists notwithstanding, no one in power in British politics is consciously developing a programme of eugenics, or writes policy where punishing disabled people is the primary aim.

Paternalism is a long-standing concern for both disability researchers and activists, with the nascent disability rights movement in Britain seeking to overcome the paternalism of disability policy built on benefits (?). (for example see Hahn 1983). Famous slogans such as 'nothing about us without us' (Charlton, 1998), or the more vulgar 'piss on pity' serve as condemnations of policies, organisations and individuals whose - often well-intentioned - treatment of disabled people serves to limit the freedom, reduce the choices available to and ultimately deny the agency of disabled people. In its most extreme forms, paternalism reduces disabled people to second-class or even third-class citizenship. Drake (as cited in 1999, ? outlined four disability policy typologies, three of which - segregation, compensation and welfare provision - are paternalistic.

There are two forms of paternalism that are relevant to disability. The first type conceives of disabled people as vulnerable and in need of external protection (in contrast to support in a rights framework), focuses on the limitations caused by a disability (without considering how social forces can exacerbate or create those limitations) and deemphasises the ability of disabled people to make choices or express preferences, particularly if they need external support to do so. The second type of paternalism, labelled the 'new paternalism' by Batavia (2001), similarly emphasises the vulnerability of disabled people, but as an oppressed minority group. Both forms of paternalism de-emphasise the autonomy, or possibilities for supported autonomy, of disabled people, and have the capacity to be very harmful to advancing the demand for independent living that lies at the heart of disability rights and politics.

The rights concept emphasises full societal participation of disabled people, in a manner that reflects the needs and expressed desires and choices of individual people; in effect enabling disabled people to engage with the world on their own terms $3^{3}$ The limitations caused by disabilities, viewed through the concept of rights, are not (or at least not exclusively) the result of the disability itself, but caused or exacerbated by society, the social model of disability. More importantly, the rights conception of disability is less concerned

\footnotetext{
${ }^{3}$ Or at least inasmuch as non-disabled people are able to participate in society on their own terms.
} 
with whether the limitations caused by a disability are intrinsic or extrinsic to the disability, and more concerned with ensuring that disabled people have the same opportunities to participate in social life and experience self-fulfilment as non-disabled people. Using the terms of the stereotype content model proposed by Fiske et al. (2002), the rights view of disability is high competency and high warmth, and the paternalist view is low competency and high warmth.

I do not mean to overstate the negatives of paternalism, and it is important to bear in mind that using paternalistic language about disability does not necessarily reflect negative attitudes to disability. It the voting record of MPs - as dictated by their party whips in most circumstances - that has a far greater impact on the day-to-day lives of disabled people than an MP's use of particular words or phrases. But taken as a collective, how MPs talk about disability issues and disabled people provides insights into public policies and public attitudes, as MPs' rhetorical approach is simultaneously influencing and influenced by the rhetoric of legislation, policy documents, the media and the general public.

\subsection{Contexts of rights and paternalism}

The increase in paternalistic conceptions of disability and accompanying decline in the use of a rights conception (see Figure 18 has occurred alongside the 'grave or systematic violations of the rights of persons with disabilities' (Committee on the Rights of Persons with Disabilities. 2016) in the UK. Barr et al. (2016a) found that reassessment of long term disability benefit claimants, using the Work Capability Assessment, led to an increase in suicides, reported mental health issues and anti-depressant prescriptions in the local area. There is no evidence to suggest that the reassessment process has led to increased employment amongst claimants, and that people with mental health issues were disproportionately likely to be moved from disability benefits to less-generous unemployment benefits (Barr et al. 2016b). Disability campaigners have highlighted the disproportionate impact of austerity on disabled people (For example see: Cross 2013 Mattheys 2015). The biopsychosocial (BPS) model of disability promulgated by Waddell and Aylward (2010), which provides much of the theoretical underpinning of post-2010 disability policy, is described by Shakespeare, Watson, and Alghaib (2017, 14) as 'conceptually and empirically invalid' with a 'barely concealed normative dimension of victim blaming' (15). Government policies have 'shrunk' the category of disability in the name of political expediency and ideological pursuits (Roulstone, 2015), and the social citizenship rights (Marshall 1950) of disabled people have been undermined and replaced with a form of 'counterfeit citizenship' (Hughes, 2015).

More general government austerity policies have also had an impact on disabled people, and are likely to have prompted concerns about 'vulnerable' members of society. Mortality rates amongst elderly people over 85 years old - another group of people often labelled 'vulnerable' - began to increase not long after the beginning of the austerity programme in 2010 (Loopstra et al. 2016), and mortality rates increased in almost all age groups between 2014 and 2015 (Green, Dorling, and Minton, 2017). The increase in paternalistic language, particularly amongst opposition parties, occurs alongside increasing volumes of evidence suggesting that disabled people have been harmed - directly and indirectly - by government policies; demanding protection for disabled people in such circumstances, including in a paternalistic fashion, is an understandable response. More cynically, an opposition MP may present themselves as a 'defender of vulnerable people' in order to draw plaudits and attention from within their party and gain increased media coverage. As Hahn (1983) pointed out 'many people who are confronted directly by the issue of disability - includ- 
ing policy makers - may react with superficial acceptance and a paternalistic desire to aid disabled persons' (45).

\subsection{Disability and vulnerability}

Paternalistic approaches to disability appear to have become more prevalent over time. The link between disability and vulnerability has become more frequent in parliamentary speeches over time. As seen in Figure 6 , there has been an increase in the number of speeches featuring disability stems that also contain vulnerability stems since 1979 . Only $2.57 \%$ of speeches mentioning disability in 1982 also mentioned vulnerability, the lowest frequency between 1979 and 2017.

By contrast, in 2015, $17.82 \%$ of speeches mentioning disability also mentioned vulnerability, the culmination of an upward trend beginning in the early 2000s. The increase in paternalistic approaches to debate about disability has been more-or-less constant; the LOES ${ }^{4}$ trend lines (dashed red) in Figure 6 and Figure 7 are very similar to the linear trend lines (solid blue) in both figures. The association between disability and vulnerability in parliamentary speeches has substantially and consistently trended upwards between 1979 and 2017, with a particular upward spike since 2010. The drop-off in 2017 is the result of the relatively small number of speeches made in 2017 , as the dataset only covers up to July 2017 and parliament was dissolved for two months for the General Election.

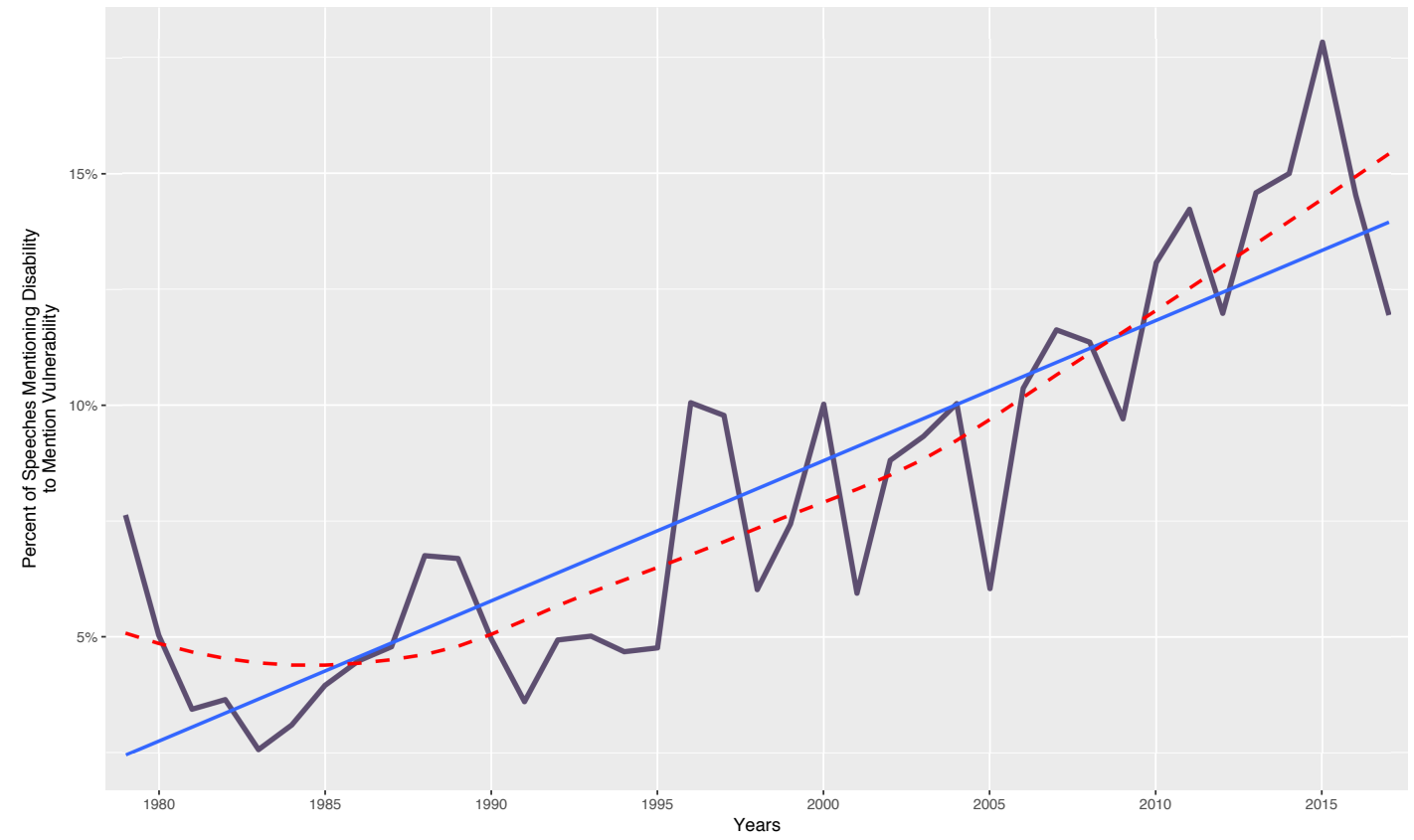

Figure 6. Percentage of speeches including 'disability' stems that also include 'vulnerable' stems. The solid blue line represents a fitted linear model, and the dashed red line represents a fitted model with LOESS smoothing.

Table 2 displays the Key Words in Context (KWIC), the number of times the word 'disability' (and stems) occurs within a given number of words (the KWIC window) of 'vulnerable' (and stems) across all speeches, and the number of speeches with a KWIC window of each size. $35.57 \%$ of all speeches to mention 'disability' and 'vulnerable' have a KWIC

\footnotetext{
${ }^{4}$ Local Regression, a form of non-parametric regression, which produces a trend line using a weighted quadratic least squares regression.
} 


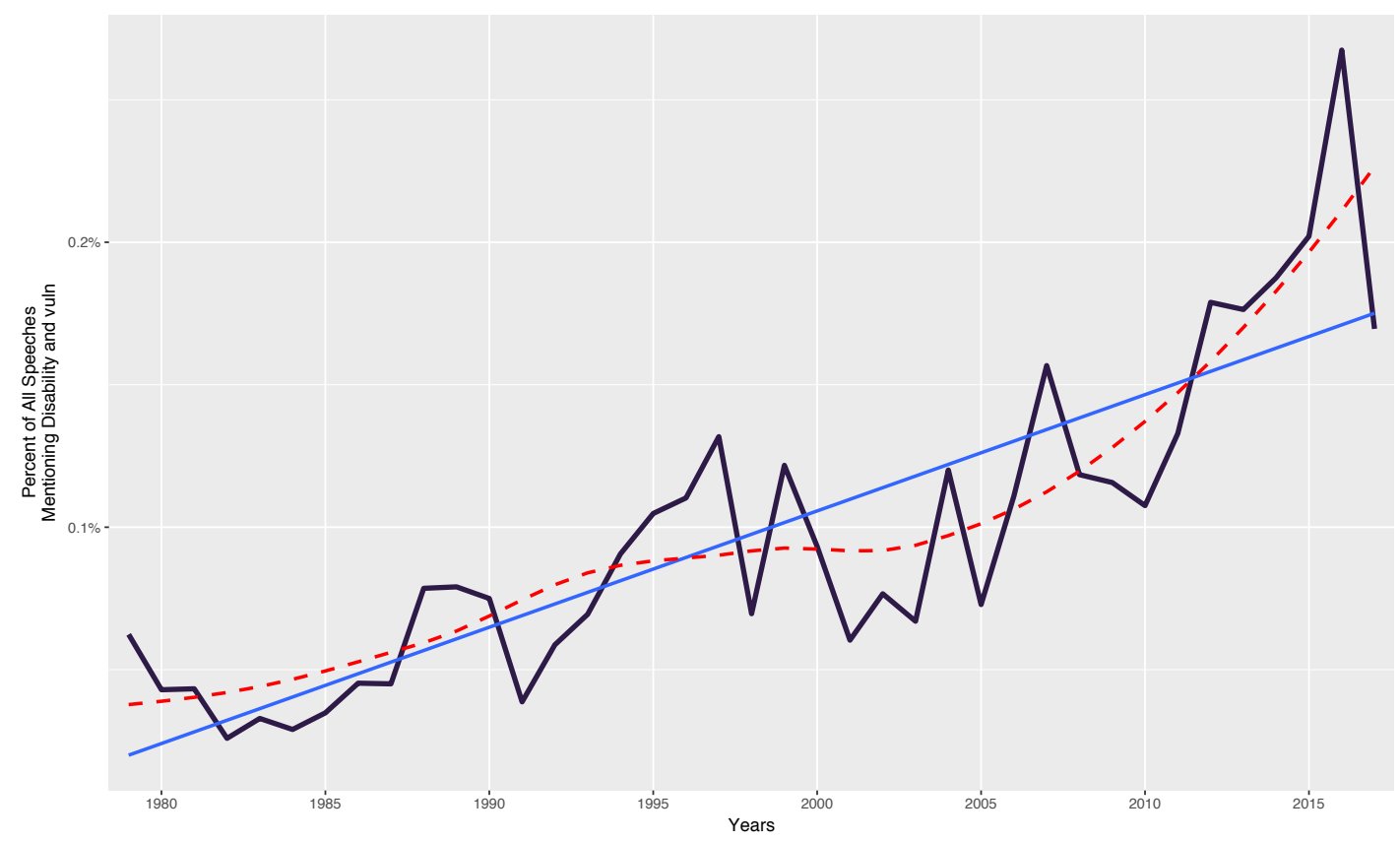

Figure 7. Percentage of all speeches including both 'disability' and 'vulnerable' stems. The solid blue line represents a fitted linear model, and the dashed red line represents a fitted model with LOESS smoothing.

Table 2. 'Disability' and 'vulnerable' in context

\begin{tabular}{lrrr}
\hline KWIC window <= & $\mathbf{5}$ & $\mathbf{1 0}$ & $\mathbf{2 0}$ \\
\hline $\begin{array}{l}\text { Occurrences within KWIC window } \\
\text { Speeches with a KWIC window of }\end{array}$ & 356 & 668 & 1,021 \\
\hline
\end{tabular}

window of less than or equal to 20 , whereas just $13.48 \%$ of speeches using both words have a KWIC window of 5 or less between them. This suggests that statements like 'disabled people are vulnerable' are rare ${ }^{5}$ but rather there is a general - and rising, as illustrated in Figure 6 and Figure 7 - association between being disabled and being vulnerable, as reflected in the rhetoric of MPs.

\subsubsection{By party}

The low number of speeches linking disability and vulnerability throughout the 1980s and 1990s makes it difficult to associate any one party with the paternalistic approach to disability. However, since 2010 there has been a clear and obvious rise in associating disability and vulnerability generally. In terms of absolute number of speeches, Labour MPs have made the most speeches with both disability and vulnerability every year from 1992-2017 (with the exception of 2015, where Conservatives MPs made more speeches). However, Labour were the largest or second largest party in the House over that time, so the absolute number of speeches tell us little.

As a percentage of speeches all speeches mentioning disability to also mention vulnerability, the Liberal Democrats were most likely to from 1996-2009. In the years since 2010, it

${ }^{5}$ In fact, that exact phrase only occurs once, on 1986-04-11, courtesy of Conservative MP for Halifax, Roy Galley. 
has been variously the Liberal Democrats, Labour, the SNP and smaller opposition parties who were most likely, when talking about disability, to also mention vulnerability (see Figure 8. In 2016 the SNP mentioned vulnerability in more than $25 \%$ of all of their speeches mentioning disability.

As a percentage of all speeches, however, it has clearly been the Labour Party and the SNP that have been the most likely to link disability and vulnerability together (see Figure 9); Close to $1 \%$ of SNP speeches in 2016 mentioned both terms.

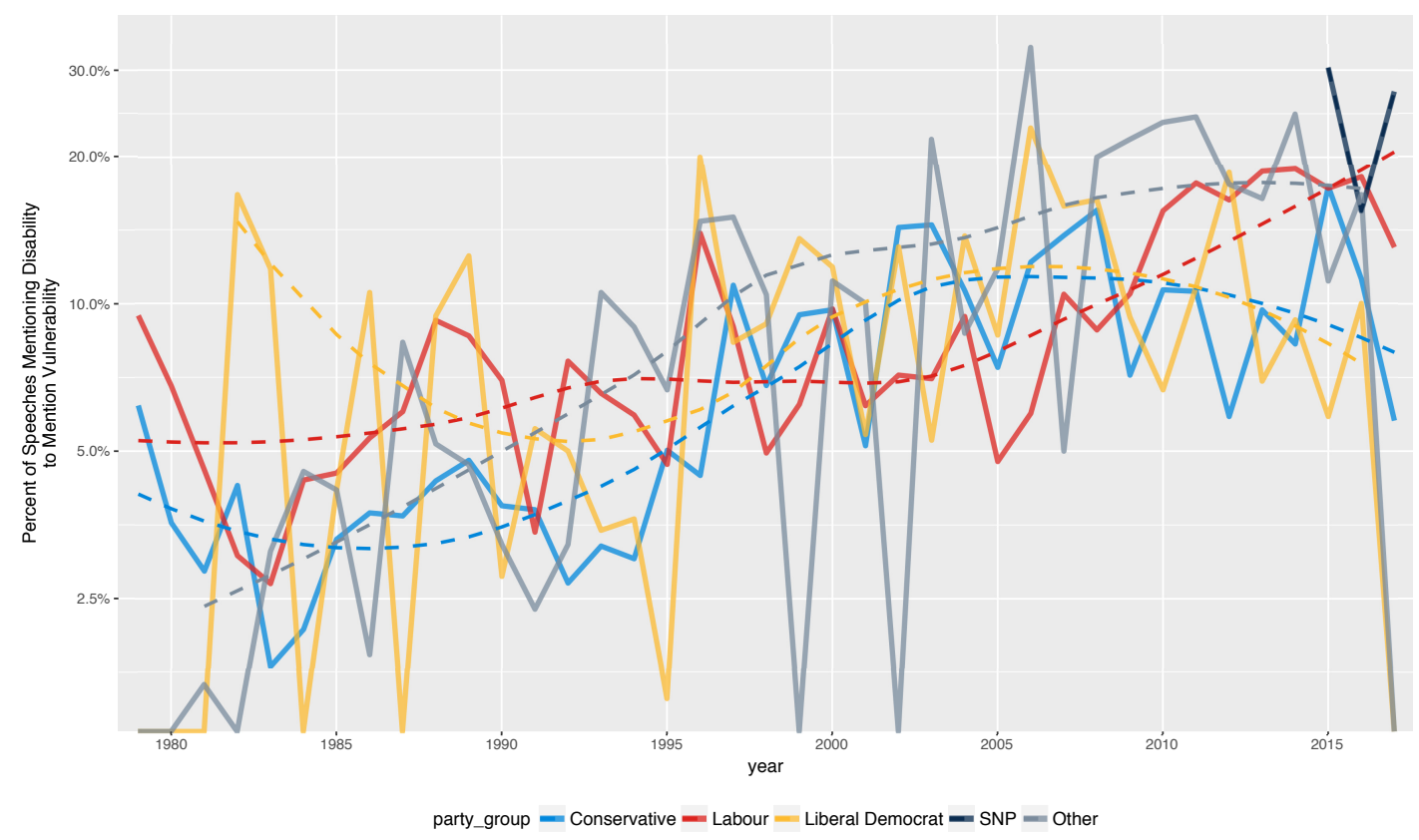

Figure 8. Percentage of speeches with 'disability' stems that also include 'vulnerable' stems, by party and year. The dashed lines represent a fitted model with LOESS smoothing. Note the logarithmic scale on the $\mathrm{x}$ axis.

\subsubsection{By government}

As with different parties, the differences between government and opposition parties become starkest after the 2010 general election, where opposition parties have driven the closer association between disability and vulnerability. Close to half a percent of all speeches made by opposition MPs in 2016 mentioned both disability and vulnerability, compared to less than one-tenth of one percent of all government speeches. Post-2010, the difference in the percentage of speeches mentioning disability to also mention vulnerability is much smaller; effectively the opposition is more likely to bring up disability than the government, and much more likely to associate it with vulnerability.

However, even prior to 2010, the opposition, regardless of whether the Conservatives or Labour were the official opposition, were much more likely to mention vulnerability when talking about disability (see Figure 10). During the Labour government of 1997-2010, there was relatively little difference between the government and opposition in terms of the total percentage of speeches mentioning both disability and vulnerability (see Figure 11), but compared to the more persistent trends shown between rights and disability in Figure 16 and Figure 17, the link to particular parties is much less clear. Rather, conflating disability and vulnerability is more a habit of oppositions, regardless of their politics. 


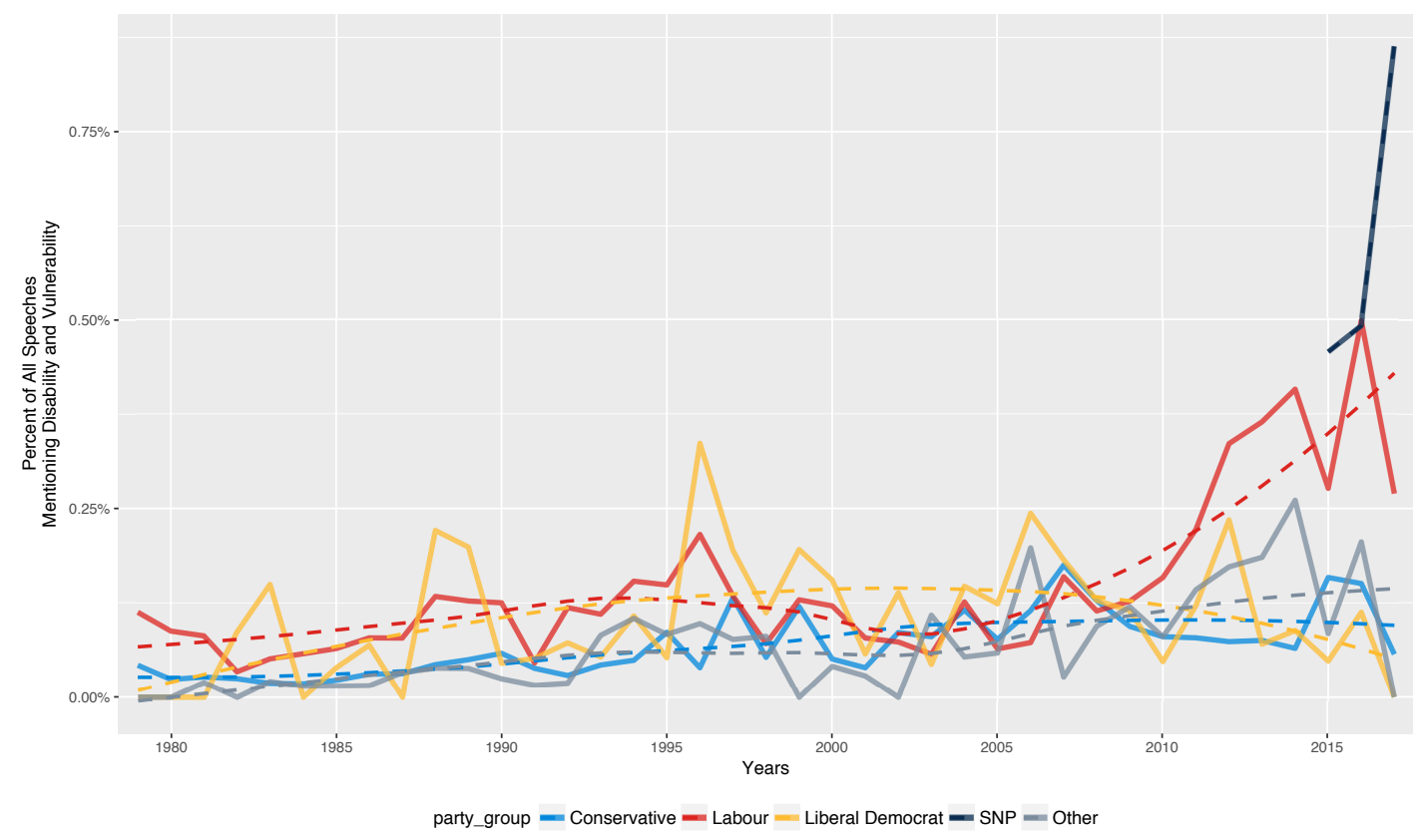

Figure 9. Percentage of all speeches with 'disability' and 'vulnerable' stems, by party and year. The dashed lines represent a fitted model with LOESS smoothing.

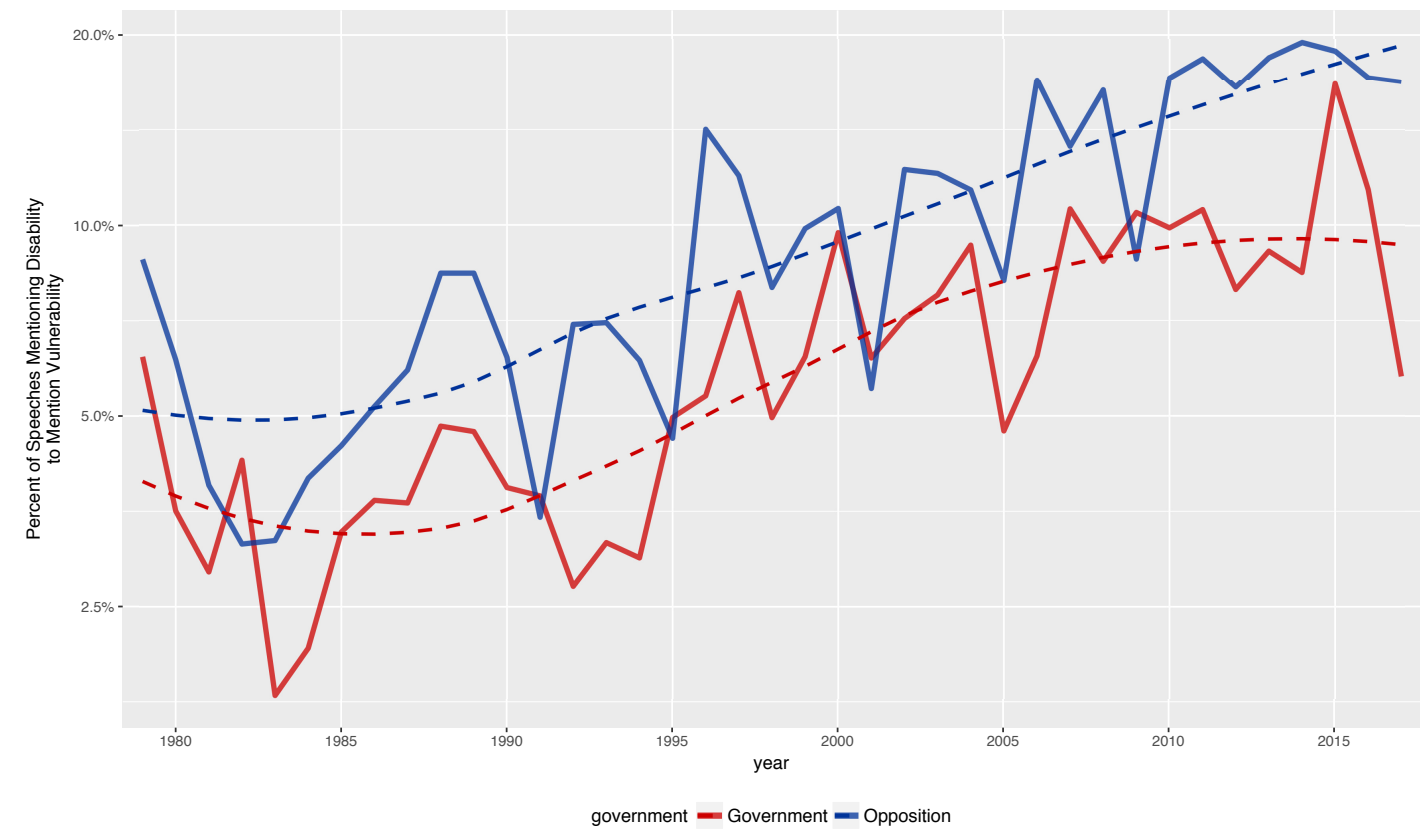

Figure 10. Percentage of speeches with 'disability' stems that also include 'vulnerable' stems, by government status and year. The dashed lines represent a fitted model with LOESS smoothing.

\subsubsection{Examples}

The notion of disabled people as needing special protections from the state is not new, as illustrated by Henry McLeish's statement below, from 1988:

Disabled people are a special group and require special discrimination in their favour. 


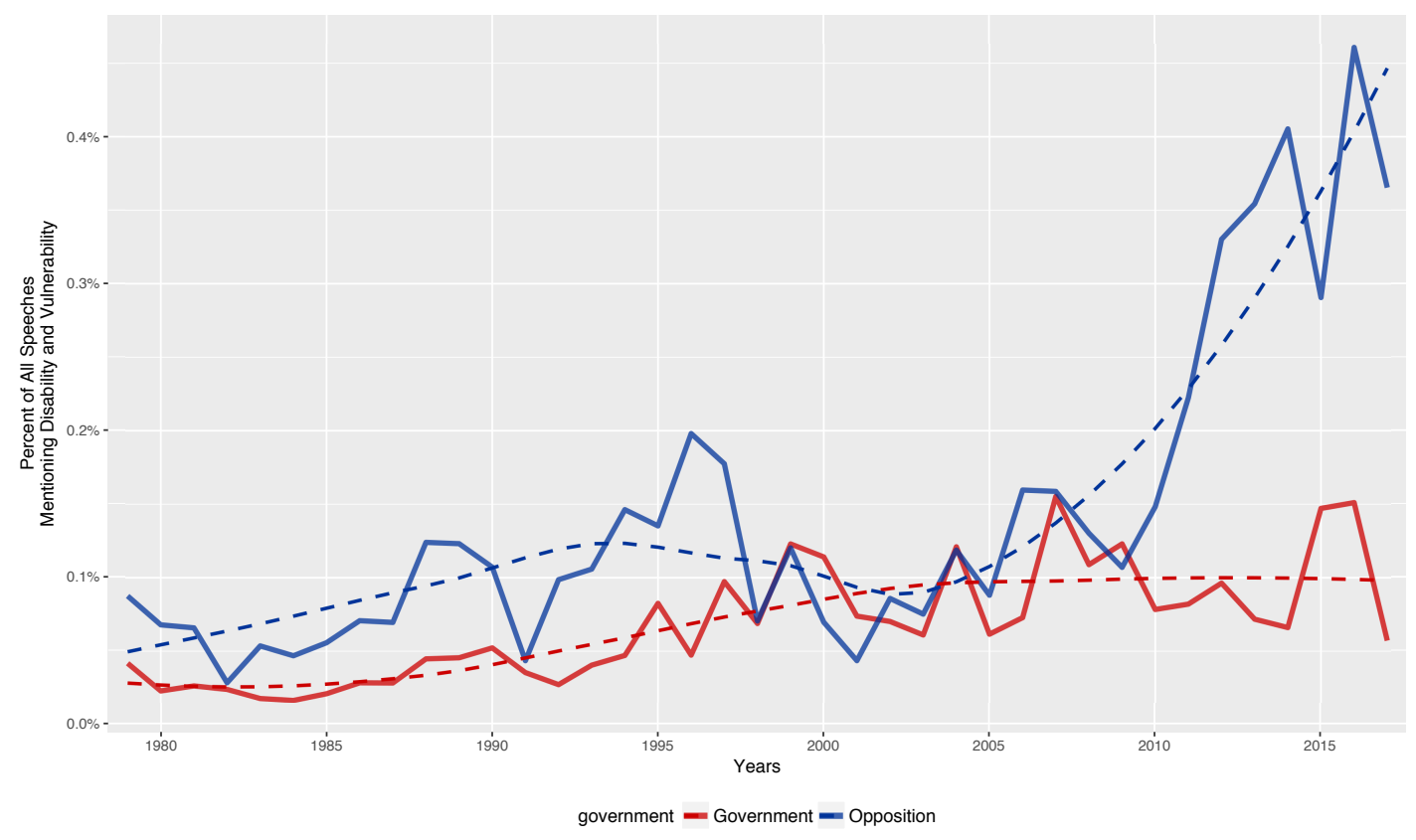

Figure 11. Percentage of all speeches with 'disability' and 'vulnerable' stems, by government status and year. The dashed lines represent a fitted model with LOESS smoothing.

- Henry McLeish, Labour MP for Central Fife, 1988-05-24

The following four quotes, from both Labour and Conservative MPs, demonstrate the paternalistic emphasis that disabled people need to be advocated for by others, rather than for themselves.

It is improper to expect confused, vulnerable, disabled and frightened consumers to take an active part in the assessment procedure unless they have someone with them who can put their point of view and help them to understand what the process is about.

- Andrew Rowe, Conservative MP for Mid Kent, 1990-03-14

The frail, the vulnerable, the elderly, the physically disabled, the mentally ill and the mentally handicapped are consumers. Unfortunately, because of the restrictions on our debate, we have not had many opportunities - we have had far too few - to discuss those groups in the context of community care.

- Tom Clarke, Labour MP for Mid Kent, 1990-03-14

This is a very sad day for the House, and more particularly for the vulnerable people in society, especially the disabled, whom the welfare state, set up all those years ago by the Beveridge reforms, was most specifically designed to help.

- Anne McIntosh, Conservative MP for Vale of York, 1999-05-20

That is a total of 800 million in round terms, which the Government propose to get from the most vulnerable, the disabled.

- Quentin Davies, Conservative MP for Grantham and Stamford, 1999-05-17

Both of the quotes from George Osbourne reflect a frequent talking point of the 20102015 coalition government and the post-2015 Conservative government; that despite cuts to welfare spending the 'most vulnerable' members of society would be protected:

... we protected the most vulnerable in our society and actually increased the amount we were 
able to give to the most disabled in our country.

- George Osbourne, Conservative MP for Tatton and Chancellor, 2015-06-04

... the welfare system should always support the elderly, the vulnerable and disabled people.

- George Osbourne, Conservative MP for Tatton and Chancellor, announcing the budget 2015-07-08

In response, opposition MPs accused austerity of harming the 'most vulnerable' members of society:

The health impacts of fuel poverty are worst for those who are most vulnerable for example, disabled people...

- Rebecca Long-Bailey, Labour MP for Salford and Eccles, 2015-07-08

Have the UK Government given any consideration at all to the impact on disabled people, who are among the most vulnerable, and will the Secretary of State confirm that there will be no erosion of their rights in the future?

- Lisa Cameron, SNP MP for East Kilbride, Strathaven and Lesmahagow, 2017-03-30

\subsection{Disability and rights}

The link between disability and rights, by contrast, appears to have risen, and then fallen away. The spike in mentions of rights in 1994-1995 accompanies the Disability Discrimination Act and debate over multiple private members bills entitled Civil Rights (Disabled Persons). In 1994, $26.73 \%$ of speeches on disability also mentioned rights, as did $26.00 \%$ of speeches on disability the following year. Figure 12 shows a rights conception of disability has been in decline over the previous decade, at least in parliamentary speeches. Although there has been a very small overall linear increase in speeches mentioning disability and rights between 1979 and 2017 (illustrated with the solid blue line), the more accurate LOESS trend line (red dashed line) shows a rise and fall in the percentage of speeches mentioning disability that also mention rights, with a peak in the mid-to-late 1990s, and a second peak in 2005.

Table 3 displays the number of times the word 'disability' occurs within each KWIC window of 'rights', and the number of speeches with at least KWIC window of each size. Just over half $(51.16 \%)$ of all speeches to mention 'disability' and 'rights' have a KWIC window of less than or equal to 20 . More strikingly, $42.52 \%$ of speeches in this group have a KWIC window of 5 or less at least once.

Table 3. 'Disability' and 'rights' in context

\begin{tabular}{lrrr}
\hline KWIC window $<=$ & $\mathbf{5}$ & $\mathbf{1 0}$ & $\mathbf{2 0}$ \\
\hline $\begin{array}{l}\text { Occurrences within KWIC window } \\
\text { Speeches with a KWIC window of }\end{array}$ & 1,372 & 2,694 & 3,136 \\
& 1,522 & 1,682 \\
\hline
\end{tabular}

The association between disability and rights was strongest in 1994 and 1995, the year the Disability Discrimination Act (DDA) was passed, with $9.27 \%$ of all speeches mentioning disability also mentioning rights (see Figure 12). More than half a percentage point of all speeches in the House of Commons in 1994 and 1995 (0.52\% and 0.57\%, respectively) mentioned both disability and rights (see Figure 13. 
There is a second spike beginning in 2015, driven by the SNP (see Figure 14 and Figure 15, who are unusual amongst the major political parties to frequently use both concepts of disability.

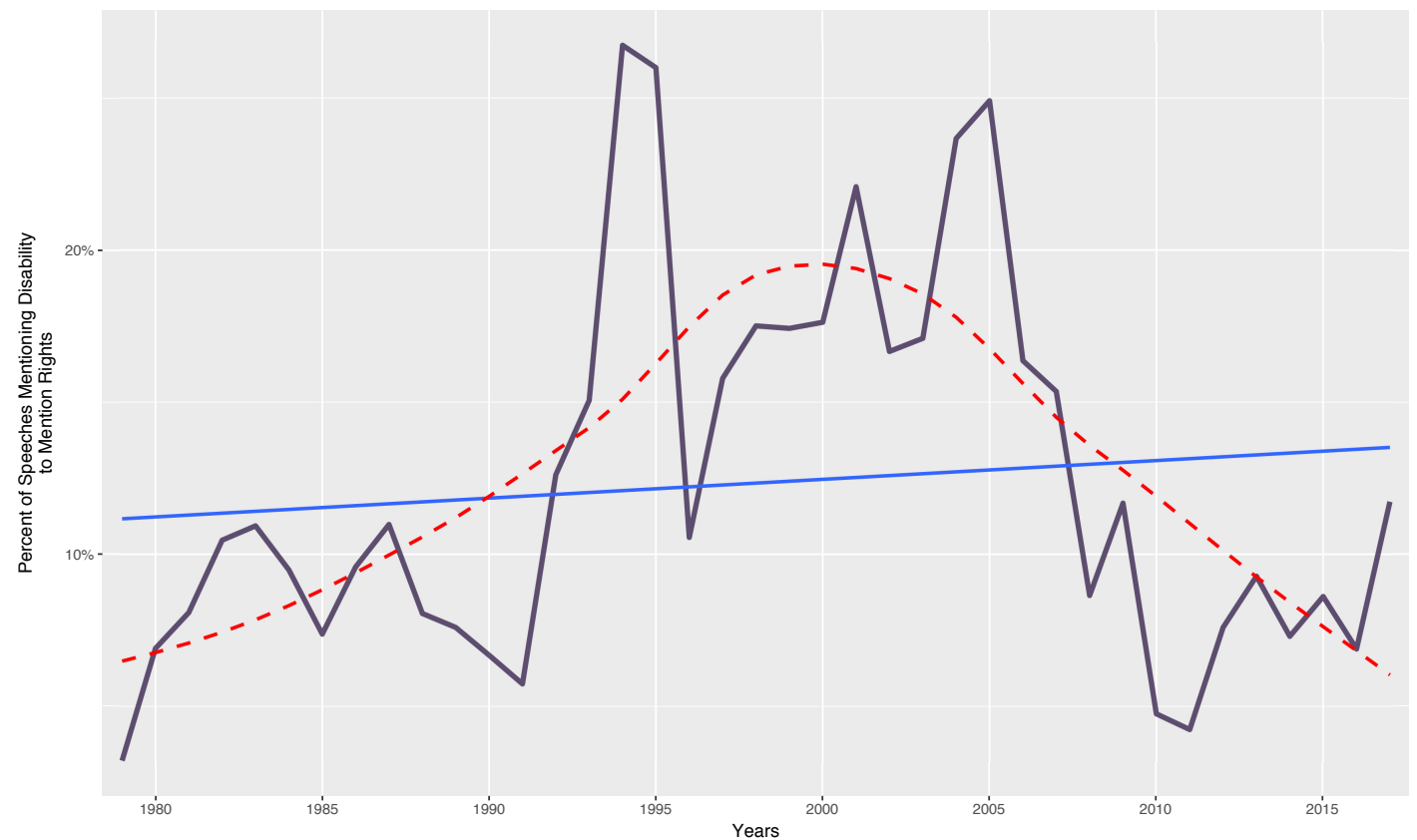

Figure 12. Percentage of speeches including 'disability' stems that also include 'rights'. The solid blue line represents a fitted linear model, and the dashed red line represents a fitted model with LOESS smoothing.

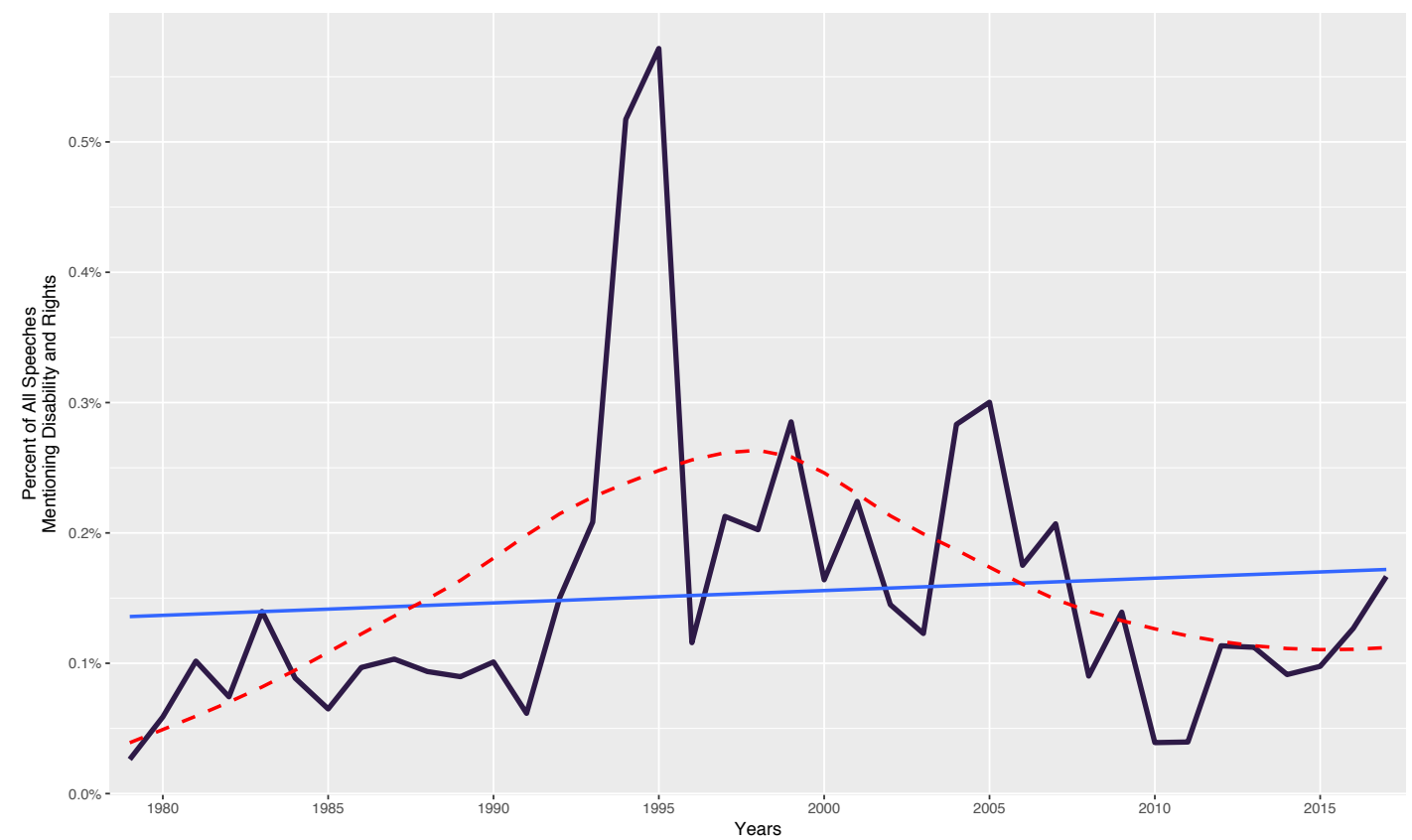

Figure 13. Percentage of all speeches including both 'disability' stems and 'rights'. The solid blue line represents a fitted linear model, and the dashed red line represents a fitted model with LOESS smoothing. 


\subsubsection{By party}

The rights conception is most strongly associated with the Labour party and the Liberal Democrats, whose MPs are consistently more likely to mention rights and disability together than MPs from other parties, as seen in Figure 8.

The spike in associating disability and rights in 1994-1995 is visible across all parties, but most clearly with the opposition Labour and Liberal Democratic parties, and to a lesser extent with the other smaller opposition parties. All parties were more or less equally as likely to associate disability and rights if talking about disability (Figure 14), and even to mention disability and rights at all (Figure 15), but the governing Conservative party were least likely to associate disability and rights, even though they were the most likely to mention disability at all in 1994 (see Figure 4 ). Roughly $1.25 \%$ of all speeches made by the Liberal Democrats in 1994 mentioned both disability and rights, as did just over 1\% of all speeches made by Labour MPs in 1995. By contrast, Conservatives MPs in 1995 only mentioned both disability and rights in just over $0.25 \%$ of all their speeches.

There does not appear to be anything inherent in the Conservative party that inhibits a rights-based approach to disability, at least amongst some members of the party (see examples below). However, the Major government's decision to ignore the various Civil Rights (Disabled Persons) private members bills introduced in the 1990s - which emphasised the positive rights of disabled people - in favour the Disability Discrimination Act, which aimed to protect disabled people from discrimination is revealing of a more paternalistic attitude to disabled people. The Conservatives are not more likely than other parties to favour a paternalistic approach to disability, nor are Labour more likely to support a rights-based approach, rather the MPs outspokenly in favour of a rights-based approach have been disproportionately Labour.

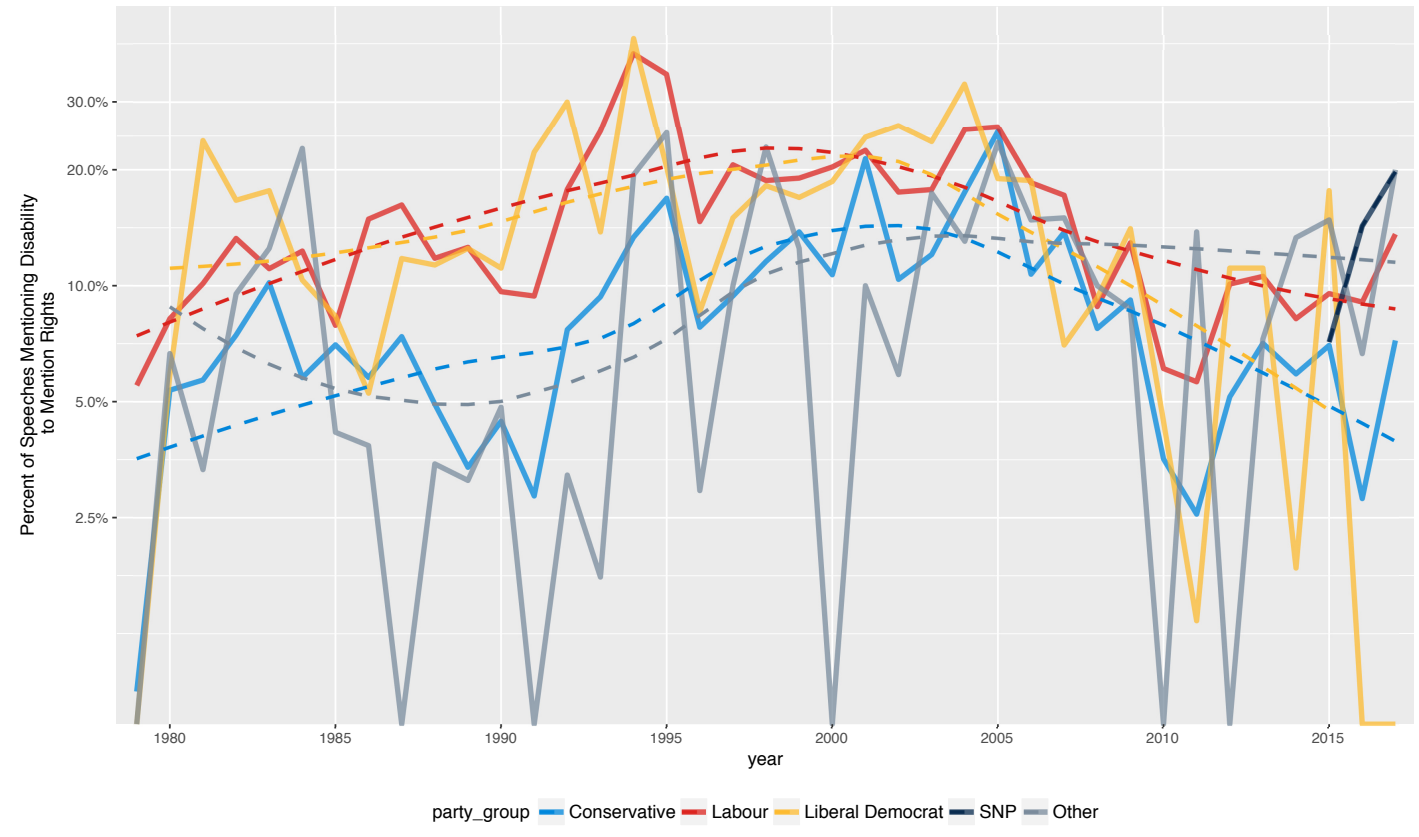

Figure 14. Percentage of speeches including 'disability' stems that also include 'rights', by party group. The dashed lines represent a fitted model with LOESS smoothing. Note the logarithmic scale on the $\mathrm{x}$ axis. 


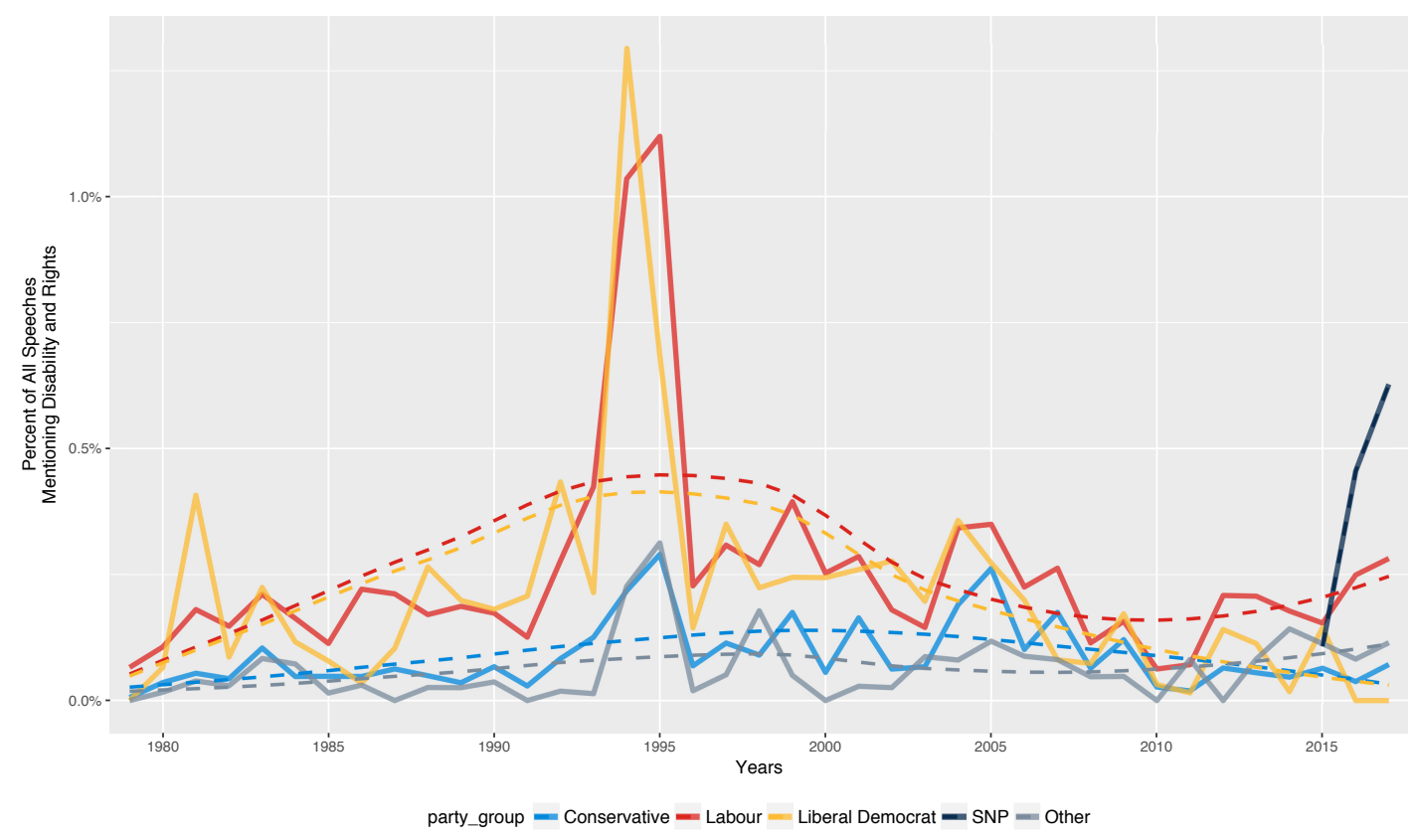

Figure 15. Percentage of all speeches that include both 'disability' stems and 'rights', by party group. The dashed lines represent a fitted model with LOESS smoothing.

\subsubsection{By government}

As expected, the government is more likely to associate disability and rights when Labour is in power. However, the difference between Labour governments and opposition parties appear to be smaller than the differences between Conservative governments and the opposition (see Figure 16 and Figure 17).

\subsubsection{Examples}

The quotes from Roger Berry, Terence Dicks and Elizabeth Lynne are illustrative of the 'positive', rights-based discourse on disability of the mid-1990s.

The aim of the Bill could not be clearer - to secure for disabled people a statutory right to protection against discrimination. It is not about charity, being paternalistic or - as someone said to me the other day - being nice to disabled people. It is about rights.

- Roger Berry, Labour MP for Kingswood, 1994-03-11, speaking in support of his Civil Rights (Disabled Persons) Bill 1994

Our duty is not to patronise disabled people, but to recognise them as our equals, respect their dignity as humans, help them to live a normal life as far as their disabilities allow and provide the resources to allow disabled civil rights to become a reality.

- Terence Dicks, Conservative MP for Hayes and Harlington, 1994-03-11

For too long debates on disability issues have been dominated by arguments about health, social security and community care. I hope that today's debate will redress that imbalance and put the issue into the realm of human rights.

- Elizabeth Lynne, Liberal Democrat MP for Rochdale, 1994-03-11

It is about all of us coming to terms with disability, removing the labels, and accepting people who are ready and able to take on the rights and responsibilities which the rest of us take for 


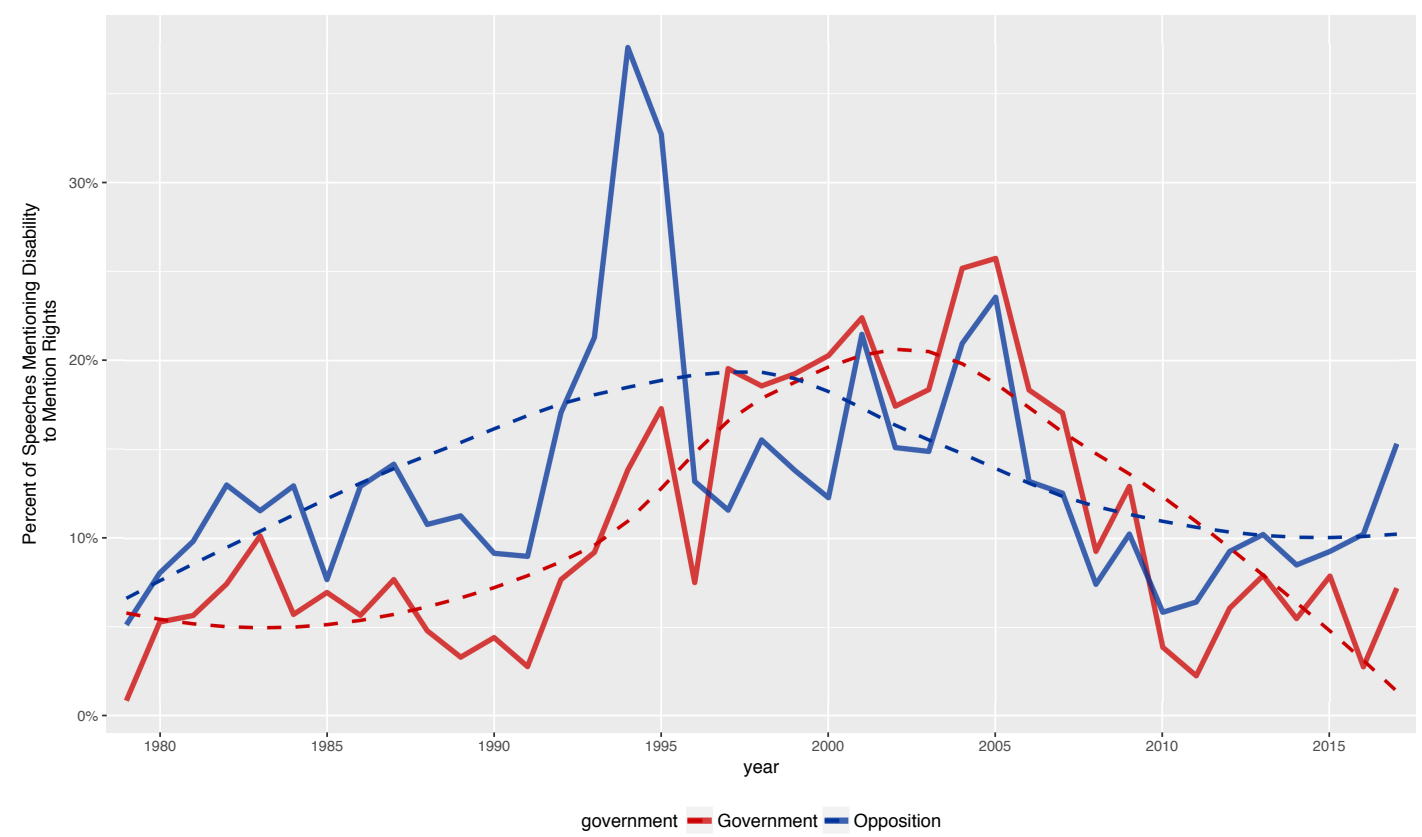

Figure 16. Percentage of speeches including 'disability' stems that also include 'rights', by government status. The dashed lines represent a fitted model with LOESS smoothing.

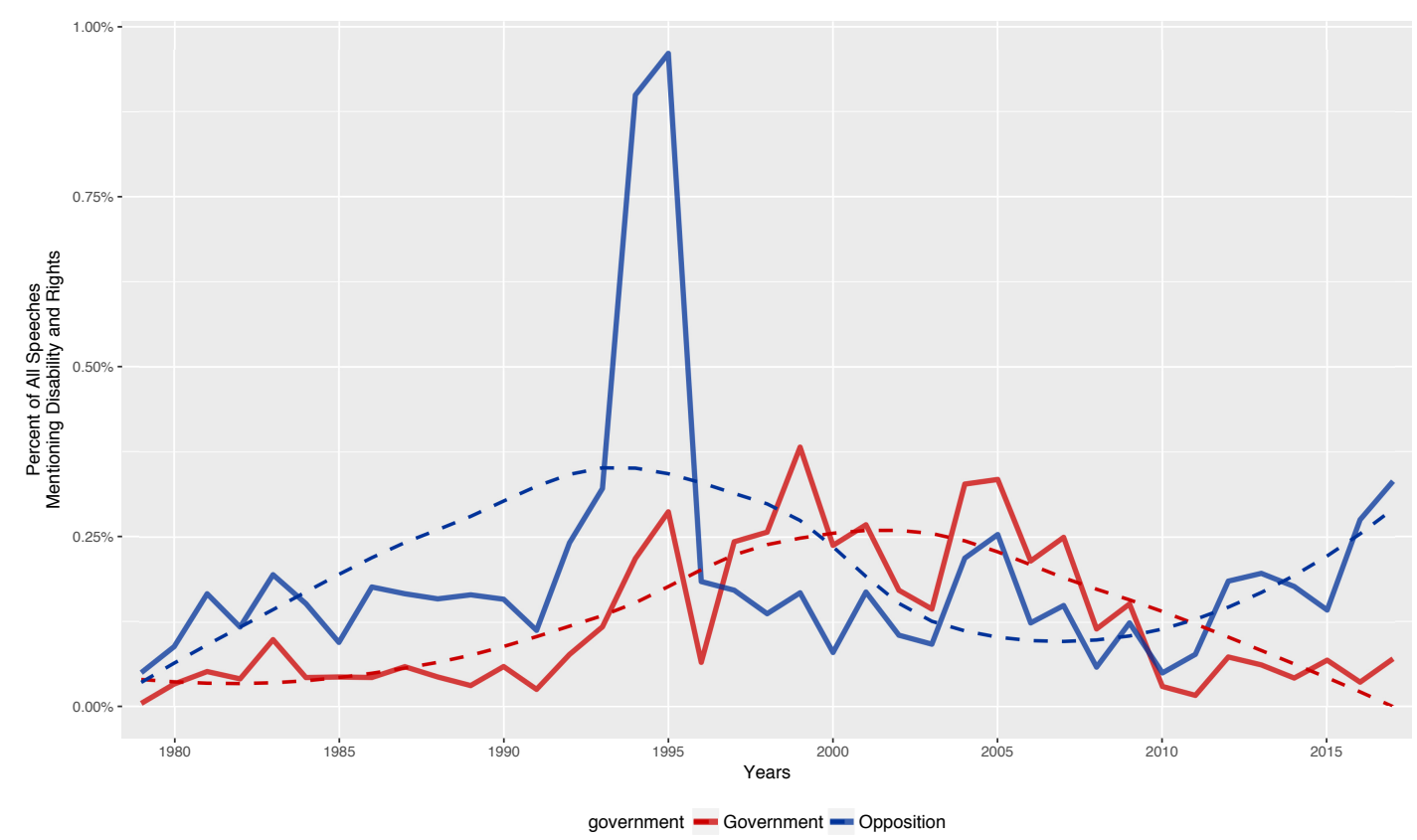

Figure 17. Percentage of all speeches that include both 'disability' stems and 'rights', by government status. The dashed lines represent a fitted model with LOESS smoothing.

granted.

- William Hague, Conservative MP for Richmond (Yorks), speaking in support of the Government's Disability Discrimination Bill, which later became the Disability Discrimination Act 1995, 1995-02-10 


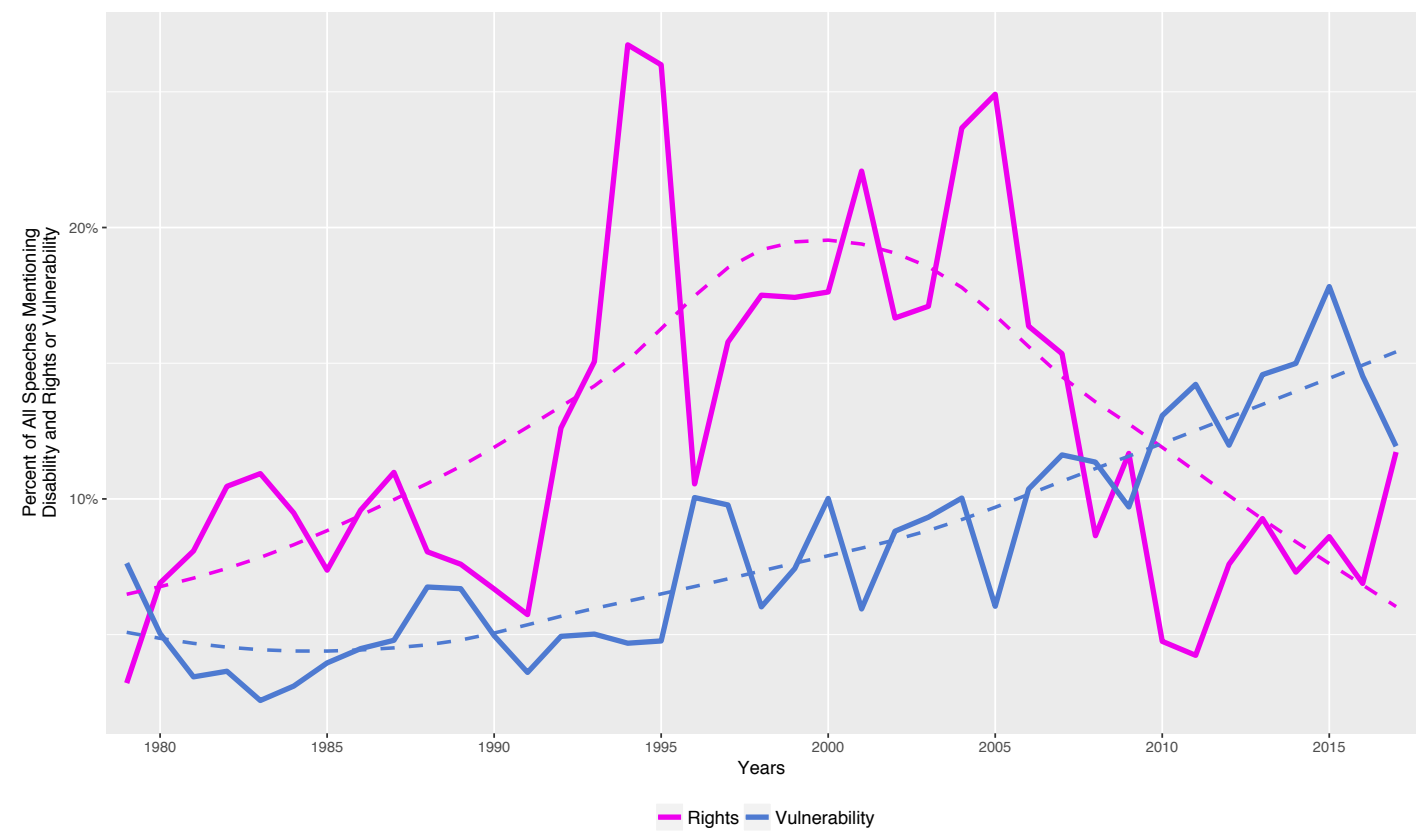

Figure 18. Percentage of all speeches that include 'disability' stems to also include 'rights' or 'vulnerability'. The dashed lines represent a fitted model with LOESS smoothing.

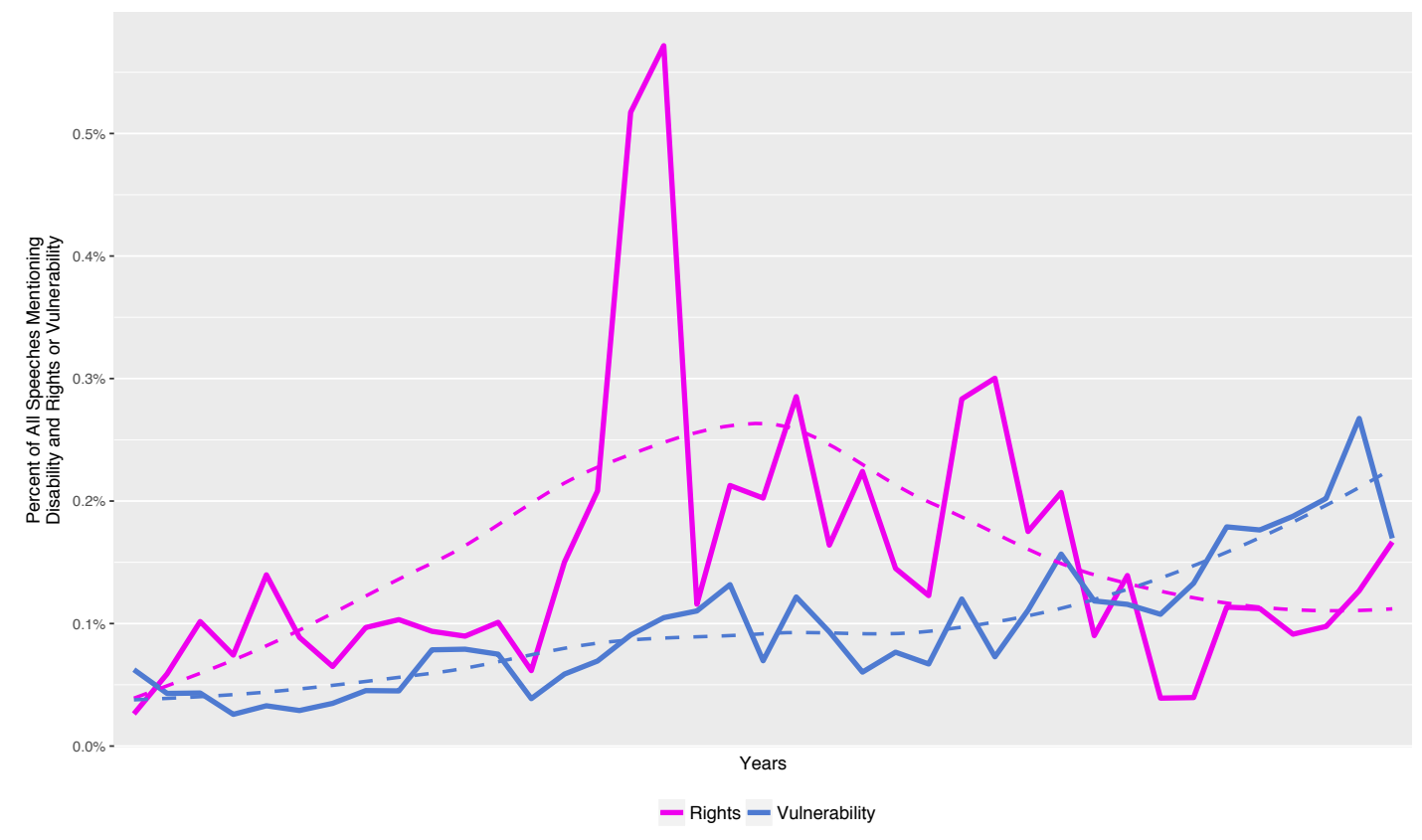

Figure 19. Percentage of all speeches that include 'disability' stems and 'rights', or 'disability' and 'vulnerability'. The dashed lines represent a fitted model with LOESS smoothing.

In my first speech to the House, I want to focus specifically on the citizenship rights of disabled people and their carers in relation to the economy and to the whole of society.

- Hywel Francis, Labour MP for Aberavon, 2001-06-25

Paul Maynard (who has cerebral palsy), highlights the possible tensions between rights and paternalism in the context of assisted suicide: 
As legislators, we should be here to protect the most vulnerable in society, but I worry that, by allowing moves towards more assisted suicides, we are not fulfilling that role. Yes, people might arrive at what they consider to be a rational decision that, because of a disability, a progressive illness or some other condition, their life is no longer worth living. With all the language of individual rights that we have heard left, right and centre today, perhaps that is where society has got to and where the currents of social change have brought us, but I fundamentally reject it.

- Paul Maynard, Conservative MP for Blackpool North and Cleveleys, during debate on assisted suicide, 2012-03-27

I hope the hon. Lady will recall that I took the Disability Discrimination Act 1995 through this Parliament and I remain passionate about the rights of disabled people.

- William Hague, Conservative MP for Richmond (Yorks), 2014-10-16

My regret about these past five years, however, is that some of the progress on disability rights has been seriously undermined, certainly in the eyes of disabled people themselves, by some of the very 'radical' - I use the word advisedly - changes in our benefits system.

- Anne McGuire, Labour MP for Stirling, 2015-03-26

The hon. Gentleman mentions my colleagues, but I remind him that the Conservative party has a proud history of protecting disability rights.

- Caroline Nokes, Conservative MP for Romsey and Southampton North, 2017-03-23

\section{Conclusion}

\subsection{Future research}

The methods used in this paper are basic by the standards of computational linguistics, as they only identify speeches that include two different terms, even disparately, and there is no deep examination of the actual content of those speeches. Comparing Table 3 and Table 2 shows there appears to be a closer association between rights and disability than vulnerability and disability, in terms of how closely together those two terms are used in speeches ${ }^{6} \mathrm{I}$ have also not compared the content of speeches mentioning disability to speeches that do not; that work will be undertaken in a future paper.

\subsection{The state as enabler}

Both of the conceptions of disability I discuss are built around differing views on the role of the state in disabled people's lives. The mid 1990s represent the peak use of 'rights' as a concept when debating disability issues, and are reflective of a political ideology that views the state as an enabler, rather than a protector. Arguments for disability rights align neatly with arguments for active labour market policies, heavy educational investment and the general withdrawal of the state from day-to-day life; in short, with New Labour. It is thus no surprise that the Labour Party had a second peak of discussing disability and rights during their period in government, and were twice as likely to mention rights as vulnerability when discussing disability (although the 2000s represented a low in mentions of disability in parliamentary debate, as well as in newspapers (Briant, Watson, and Philo, 2013)). Labour was closely matched and sometimes surpassed in the frequency of speeches men-

${ }^{6}$ This at least partially the result of references to bills and organisations as discussed above 
tioning rights and disability by the Liberal Democrats, and although Labour is persistently more likely to mention rights when talking about disability relative to the Conservatives and other parties, the actual difference is rarely very large (see Figure 14 and Figure 15.

The rights conception of the state is Thatcherite, inasmuch as it wants the state to create the conditions for disabled people's participation in society on an equal basis with non-disabled people, but passes primary responsibility for that societal participation to disabled people themselves. Disability researchers have previously noted that neoliberal small-state social policy and disability rights campaigning share not just form and rhetoric, but political and practical content (Mladenov, 2015 ?). 'Choice and control' is just one such example; the cleavage between neoliberalism and the goals of the independent living movement is over universal access to services and the degree to which service users have a legal and social right to exercise choice over those services, Oliver (1989) notes. The issue with neoliberalism is not the rhetoric of choice that permeates all its various flavours, but neoliberalism's fundament inability to make good on its promises of choice and control.

\subsection{The state as protector}

In contrast to the rights conception of disability, the paternalistic conception of disability views the state as responsible for protecting disabled people - both from external harms and from themselves - with a level of protection not applied to non-disabled people. Rather than legal protection against discrimination, the paternalistic conception aims to eliminate risk for disabled people, a task that is only truly possible when disabled people are barred from doing virtually anything in the interests of their own safety. The increase in association between disabled people and vulnerability is symptomatic of a retreat from the arena of rights in favour of defending the welfare state, a tactical and strategic change embraced both by disabled and sympathetic MPs and by activist groups such as DPAC. They are not wrong to identify that disabled people are vulnerable - the impact of austerity briefly outlined above has fallen disproportionately on disabled people - but the rhetoric affirms that vulnerability, when the aim is surely to overcome vulnerability.

Since 2010, a paternalistic conception of disabled people has dominated political debate in the House of Commons, driven by opposition parties, namely Labour and the SNP, in response to government austerity policies. This response - while understandable given the impact of austerity policies - considers disabled people to be reliant on the welfare state (which many are or have been). Political opposition to austerity, both inside and outside parliament, focuses on defending existing welfare state provisions, and demanding a return to how it previously was (or was imagined to be), rather than imagining what the welfare state could be for disabled people, or seeking to get beyond reliance on the welfare state.

I do not wish to overstate the rise of paternalism - the use of paternalistic language to refer to disabled people in parliament has increased, but it remains only a small proportion of all the language used to refer to disabled people. What is more worrying is the apparent fall in use of a rights-based conception of disabled people. Such a conception could just as easily be invoked in defence of the welfare state; it remains unclear why opposition parties have seized the mantle of paternalism rather than rights on this issue, aside from it being a long-standing tactic of opposition parties. 


\subsection{The future of disability politics}

I want to conclude with a few thoughts on what - if any - political content can be seen in this analysis, and the implications of the apparently increasingly paternalistic view taken towards disabled people by parliamentarians. The increasing use of words like vulnerability when discussing disabled people appears to be in line with other attempts to defend the welfare state in an era of austerity. For example, research on benefits stigma interprets it as a problem to be solved by a more generous and humane welfare state (e.g. Baumberg Geiger, 2016 Garthwaite, 2015a b: Taylor-Gooby, 2013), or occasionally a solution to problems of unemployment and socio-economic deprivation exacerbated by 'long-term welfare dependency' (Murray, 1996).

The question of paternalism, like the question of stigma, is centred on the welfare state. Is the welfare state to be affirmed, defended and expanded, as a fundamentally emancipatory force, as argued by an seemingly all disability activists, campaigners and academics? Or should it be condemned as an obstacle that has done more harm than good and outlived any usefulness it may have, at least as it has traditionally and is currently configured, for example as suggested by Mead (1997) in the United States, and think tanks such as the Centre for Welfare Reform and the Institute of Economic Affairs in the UK?

In the context of disability, condemnations of the welfare state as an obstacle should be taken seriously by disabled people. There is emancipatory potential for disabled people in the welfare state, but that emancipation is contingent and precarious, subject to the whims of government. The great problem of austerity (in terms of disabled people) is not the desire to have fewer disabled people claiming benefits, but is the inhumane and backward manner in which current, former and potential benefit claimants are being treated. Rather than opening up economic opportunities for disabled people to reduce their reliance on the welfare state, government policies have simply restricted state support without any effort to create conditions where disabled people (or at least more disabled people) would be able to live without long-term dependence on the welfare state.

\section{Acknowledgement(s)}

Thank you to Liz Sayce for asking me if it was possible to see how often 'disability' and 'vulnerable' were collocated in parliamentary speeches, which inspired this paper. An earlier version of Figure 19 was included in a presentation by Liz Sayce at the International Inequalities Institute at the LSE on 14 June 2017.

\section{Disclosure statement}

There are no conflicts of interest to report.

\section{Notes on contributor(s)}

Evan Odell is a researcher at Disability Rights UK. ORCiD: https://orcid.org/0000-0003-1845-808X

Website:https://evanodell.com/

Twitter:https://twitter.com/evanodell 


\section{References}

Audickas, Lukas, Oliver Hawkins, and Richard Cracknell. 2017. UK Election Statistics: 1918-2017. Briefing Paper CBP7529. London: House of Commons Library. http://researchbriefings . parliament.uk/ResearchBriefing/Summary/CBP-7529.

Barr, B., D. Taylor-Robinson, D. Stuckler, R. Loopstra, A. Reeves, and M. Whitehead. 2016a. "First, Do No Harm': Are Disability Assessments Associated with Adverse Trends in Mental Health? A Longitudinal Ecological Study." Journal of Epidemiology and Community Health 70 (4): 339-345. Accessed 2017-07-12. http://jech.bmj.com/content/70/4/339. abstract.

Barr, B., D. Taylor-Robinson, D. Stuckler, R. Loopstra, A. Reeves, S. Wickham, and M. Whitehead. 2016b. "Fit-for-Work or Fit-for-Unemployment? Does the Reassessment of Disability Benefit Claimants Using a Tougher Work Capability Assessment Help People into Work?" J Epidemiol Community Health 70 (5): 452-458. Accessed 2017-07-12. http://jech.bmj.com/content/ 70/5/452.short

Batavia, Andrew I. 2001. "The New Paternalism: Portraying People with Disabilities as an Oppressed Minority." Journal of Disability Policy Studies 12 (2): 107-113. Accessed 2017-07-14. http://journals.sagepub.com/doi/abs/10.1177/104420730101200208.

Baumberg Geiger, Ben. 2016. "The Stigma of Claiming Benefits: A Quantitative Study." Journal of Social Policy 45 (02): 181-199. Accessed 2017-07-12. http://www . journals . cambridge . org/ abstract_S0047279415000525.

Benoit, Kenneth, Kohei Watanabe, Paul Nulty, Adam Obeng, Haiyan Wang, Benjamin Lauderdale, and Will Lowe. 2017. "Quanteda: Quantitative Analysis of Textual Data." http://quanteda .io.

Braye, Stuart, Kevin Dixon, and Tom Gibbons. 2013. “'A Mockery of Equality': An Exploratory Investigation into Disabled Activists' Views of the Paralympic Games." Disability \& Society 28 (7): 984-996. Accessed 2017-06-21. http://www.tandfonline.com/doi/abs/10.1080/ 09687599.2012 .748648

Briant, Emma, Nick Watson, and Gregory Philo. 2013. "Reporting Disability in the Age of Austerity: The Changing Face of Media Representation of Disability and Disabled People in the United Kingdom and the Creation of New 'Folk Devils.'” Disability \& Society 28 (6): 874-889. Accessed 2017-06-21.http://www.tandfonline.com/doi/abs/10.1080/09687599.2013.813837.

Charlton, James I. 1998. Nothing about Us without Us: Disability Oppression and Empowerment. University Press Scholarship Online. Berkeley: University of California Press.

Committee on the Rights of Persons with Disabilities. 2016. Inquiry Concerning the United Kingdom of Great Britain and Northern Ireland Carried out by the Committee under Article 6 of the Optional Protocol to the Convention. Technical Report CRPD/C/15/R.2/Rev.1. Geneva: Office of the United Nations High Commissioner for Human Rights. http://www.ohchr.org/Documents/ HRBodies/CRPD/CRPD.C.15.R.2.Rev.1-ENG.doc

Connor, Stuart. 2010. "Promoting 'Employ Ability': The Changing Subject of Welfare Reform in the UK." Critical Discourse Studies 7 (1): 41-54. Accessed 2017-06-21. http://www.tandf online. com/doi/abs/10.1080/17405900903453930.

Cross, Merry. 2013. "Demonised, Impoverished and Now Forced into Isolation: The Fate of Disabled People under Austerity." Disability \& Society 28 (5): 719-723. Accessed 2017-07-12. http://www . tandfonline.com/doi/abs/10.1080/09687599.2013.808087.

Donoghue, Matthew. 2013. "Welfare and Cohesion Contested: A Critical Discourse Analysis of New Labour's Reform Programme." British Politics 8 (1): 79-100. Accessed 2017-08-25.http://link. springer.com/article/10.1057/bp.2012.23

Drake, Robert F. 1999. Understanding Disability Policies. Basingstoke: Macmillan. OCLC: ocm41255290.

Fiske, Susan T., Amy J. C. Cuddy, Peter Glick, and Jun Xu. 2002. "A Model of (Often Mixed) Stereotype Content: Competence and Warmth Respectively Follow from Perceived Status and Competition." Journal of Personality and Social Psychology 82 (6): 878-902. Accessed 2017-07-07.http://doi . apa.org/getdoi.cfm?doi=10.1037/0022-3514.82.6.878

Garrett, Paul Michael. 2015. "Words Matter: Deconstructing 'welfare Dependency' in the UK." Critical and Radical Social Work 3 (3): 389-406. Accessed 2017-08-25. http://openurl. ingenta. 
com/content/xref?genre=article\&issn=2049-8608\&volume=3\&issue=3\&spage=389.

Garthwaite, Kayleigh. 2011. “The Language of Shirkers and Scroungers?' Talking about Illness, Disability and Coalition Welfare Reform.” Disability \& Society 26 (3): 369-372. Accessed 2017-01-17. http://www.tandfonline.com/doi/abs/10.1080/09687599.2011.560420

Garthwaite, Kayleigh. 2015a. "Becoming Incapacitated? Long-Term Sickness Benefit Recipients and the Construction of Stigma and Identity Narratives.” Sociology of Health \& Illness 37 (1): 1-13. Accessed 2017-06-21.http://doi .wiley.com/10.1111/1467-9566.12168

Garthwaite, Kayleigh. 2015b. "'Keeping Meself to Meself’ - How Social Networks Can Influence Narratives of Stigma and Identity for Long-Term Sickness Benefits Recipients.” Social Policy \& Administration 49 (2): 199-212. Accessed 2017-08-20. http://doi.wiley.com/10.1111/spol. 12119

Green, Mark, Danny Dorling, and Jon Minton. 2017. “The Geography of a Rapid Rise in Elderly Mortality in England and Wales, 2014-15.” Health \& Place 44: 77-85. Accessed 2017-07-12. http: //linkinghub.elsevier.com/retrieve/pii/S1353829216303367.

Hahn, Harlan. 1983. "Paternalism and Public Policy." Society 20 (3): 36-46. Accessed 2017-07-14. http://www.springerlink.com/index/M80NGMU45454652J.pdf.

Haller, Beth, Bruce Dorries, and Jessica Rahn. 2006. "Media Labeling versus the US Disability Community Identity: A Study of Shifting Cultural Language.” Disability \& Society 21 (1): 61-75. Accessed 2017-06-22. https://www.tandfonline.com/doi/full/10.1080/ 09687590500375416 .

Hughes, Bill. 2015. "Disabled People as Counterfeit Citizens: The Politics of Resentment Past and Present." Disability \& Society 30 (7): 991-1004. Accessed 2017-09-20. http://www . tandfonline.com/doi/full/10.1080/09687599.2015.1066664.

Jensen, Tracey. 2014. "Welfare Commonsense, Poverty Porn and Doxosophy." Sociological Research Online 19 (3): 1-7. Accessed 2017-08-20. http: //journals . sagepub . com/doi/10.5153/sro. 3441 .

Jensen, Tracey, and Imogen Tyler. 2015. “'Benefits Broods': The Cultural and Political Crafting of Anti-Welfare Commonsense.” Critical Social Policy 35 (4): 470-491. Accessed 2017-08-20. http: //journals.sagepub.com/doi/abs/10.1177/0261018315600835.

Loopstra, Rachel, Martin McKee, Srinivasa Vittal Katikireddi, David Taylor-Robinson, Ben Barr, and David Stuckler. 2016. "Austerity and Old-Age Mortality in England: A Longitudinal Cross-Local Area Analysis, 2007-2013.” Journal of the Royal Society of Medicine 109 (3): 109-116. Accessed 2017-07-12.http://journals. sagepub.com/doi/10.1177/0141076816632215.

Luchinskaya, Daria, Polly Simpson, and George Stoye. 2017. "UK Health and Social Care Spending." In IFS Green Budget 2017, 141-176. London: Institute for Fiscal Studies. https : //www . ifs . org . uk/uploads/publications/budgets/gb2017/gb2017ch5.pdf.

Marshall, Thomas H. 1950. Citizenship and Social Class. Cambridge: Cambridge University Press. 06308.

Mattheys, Kate. 2015. “The Coalition, Austerity and Mental Health.” Disability \& Society 30 (3): 475478. Accessed 2017-07-12. http://www.tandfonline.com/doi/full/10.1080/09687599. 2014.1000513

Mead, Lawrence M. 1997. "Citizenship and Social Policy: TH Marshall and Poverty.” Social Philosophy and Policy 14 (2): 197-230.

Mladenov, Teodor. 2015. “Neoliberalism, Postsocialism, Disability.” Disability \& Society 30 (3): 445459. Accessed 2017-08-25. http://www.tandfonline.com/doi/full/10.1080/09687599. 2015.1021758

Murray, Charles A. 1996. Charles Murray and the Underclass: The Developing Debate. London: Institute of Economic Affairs Health and Welfare Unit. OCLC: 36260616.

Office for National Statistics, National Records of Scotland, and Northern Ireland Statistics and Research Agency. 2017. "2011 Census Aggregate Data. (Edition: February 2017).” https://www.ons.gov.uk/ peoplepopulationandcommunity/populationandmigration/populationestimates/ bulletins/keystatisticsandquickstatisticsforlocalauthoritiesintheunitedkingdom/ 2013-10-11 
Oliver, Michael. 1983. Social Work with Disabled People. 1st ed. London: Macmillan.

Oliver, Mike. 1989. “Disability and Dependency: A Creation of Industrial Societies.” In Disability and Dependency, edited by Len Barton, Disability, handicap, and life chances, 6-22. London: RoutledgeFalmer.

Rheault, Ludovic, Kaspar Beelen, Christopher Cochrane, and Graeme Hirst. 2016. "Measuring Emotion in Parliamentary Debates with Automated Textual Analysis." PLOS ONE 11 (12): e0168843. Accessed 2017-06-25. http://journals.plos.org/plosone/article?id= 10.1371/journal.pone.0168843.

Roulstone, Alan. 2015. "Personal Independence Payments, Welfare Reform and the Shrinking Disability Category.” Disability \& Society 30 (5): 673-688. Accessed 2017-09-20. http://www . tandfonline.com/doi/full/10.1080/09687599.2015.1021759.

Roulstone, Alan, and Hannah Morgan. 2009. "Neo-Liberal Individualism or Self-Directed Support: Are We All Speaking the Same Language on Modernising Adult Social Care?" Social Policy and Society 8 (03): 333. Accessed 2017-08-25. http://www . journals . cambridge.org/abstract_ S1474746409004886

Schmidt, Vivien A. 2002. "Does Discourse Matter in the Politics of Welfare State Adjustment?" Comparative political studies 35 (2): 168-193. Accessed 2017-06-22. http://journals.sagepub. com/doi/abs/10.1177/0010414002035002002

Shakespeare, Tom. 1994. "Cultural Representation of Disabled People: Dustbins for Disavowal?" Disability \& Society 9 (3): 283-299. Accessed 2017-07-12. https://www.tandfonline.com/ doi/full/10.1080/09687599466780341

Shakespeare, Tom, Nicholas Watson, and Ola Abu Alghaib. 2017. "Blaming the Victim, All over Again: Waddell and Aylward's Biopsychosocial (BPS) Model of Disability.” Critical Social Policy 37 (1): 22-41. Accessed 2017-07-12. http://journals . sagepub.com/doi/abs/10.1177/ 0261018316649120

Swain, John, and Sally French. 2000. “Towards an Affirmation Model of Disability.” Disability \& Society 15 (4): 569-582. Accessed 2017-10-09. http://www.tandfonline.com/doi/abs/10.1080/ 09687590050058189 .

Taylor-Gooby, Peter. 2013. "Why Do People Stigmatise the Poor at a Time of Rapidly Increasing Inequality, and What Can Be Done about It?” The political quarterly 84 (1): 31-42.

Waddell, Gordon, and Mansel Aylward. 2010. Models of Sickness and Disability: Applied to Common Health Problems. Royal Society of Medicine Press.

Waldschmidt, Anne. 2017. "Disability Goes Cultural: The Cultural Model of Disability as an Analytical Tool.” In Culture-Theory-Disability: Encounters between Disability Studies and Cultural Studies, edited by Anne Waldschmidt, Hanjo Berressem, and Moritz Ingwersen, Disability Studies Volume 10, 19-27. Bielefeld: Transcript.

Wickham, Hadley. 2016. ggplot2: Elegant Graphics for Data Analysis. Springer-Verlag New York. http://ggplot2.org.

Wilde, Alison. 2014. "Spectacle, Performance, and the Re-Presentation of Disability and Impairment." Review of disability studies: an international journal 6 (3). Accessed 2017-06-22. http: //www.rdsjournal.org/index.php/journal/article/view/161.

\section{Appendices}


Table 4. Percentage of speeches made by Alan Howarth that reference disability before and after crossing the floor from the Conservatives to Labour

\begin{tabular}{lrrr}
\hline \multicolumn{1}{c}{ Party } & $\begin{array}{c}\text { Number of Speeches } \\
\text { Referencing Disability }\end{array}$ & Total Speeches & $\begin{array}{c}\text { Percentage of Speeches } \\
\text { Referencing Disability }\end{array}$ \\
\hline Conservative & 80 & 744 & $10.75 \%$ \\
Labour & 47 & 319 & $12.84 \%$ \\
Total & 127 & 1110 & $11.44 \%$ \\
\hline
\end{tabular}

